\title{
Enhancement of Intracellular Calcium Ion Mobilization by Moderately but Not Highly Positive Material Surface Charges
}

\author{
Martina Gruening ${ }^{1}$, Sven Neuber ${ }^{2}$, Peter Nestler2, Jutta Lehnfeld ${ }^{3}$, Manuela Dubs ${ }^{4}$, \\ Katja Fricke ${ }^{5}$, Matthias Schnabelrauch ${ }^{4}$, Christiane A. Helm², Rainer Müller ${ }^{3}$, \\ Susanne Staehlke ${ }^{1}$ and J. Barbara Nebe ${ }^{1,6 *}$
}

${ }^{1}$ Department of Cell Biology, Rostock University Medical Center, Rostock, Germany, ${ }^{2}$ Soft Matter and Biophysics, Institute of Physics, University of Greifswald, Greifswald, Germany, ${ }^{3}$ Colloid and Interface Chemistry, Institute of Physical and Theoretical Chemistry, University of Regensburg, Regensburg, Germany, ${ }^{4}$ Department of Biomaterials, INNOVENT e.V., Jena, Germany, ${ }^{5}$ Leibniz Institute for Plasma Science and Technology e.V. (INP), Greifswald, Germany, ${ }^{6}$ Department Science and Technology of Life, Light and Matter, Faculty of Interdisciplinary, University of Rostock, Rostock, Germany

\section{OPEN ACCESS}

Edited by:

Masoud Mozafari,

University of Toronto, Canada

Reviewed by:

Thomas Michael Groth,

Martin Luther University

Halle-Wittenberg, Germany

Bogdan Parakhonskiy,

Ghent University, Belgium

*Correspondence:

J. Barbara Nebe

barbara.nebe@med.uni-rostock.de

\section{Specialty section: \\ This article was submitted to Biomaterials, \\ a section of the journal Frontiers in Bioengineering and Biotechnology}

Received: 19 May 2020 Accepted: 03 August 2020 Published: 08 September 2020

Citation:

Gruening M, Neuber S, Nestler $P$, Lehnfeld J, Dubs M, Fricke K, Schnabelrauch M, Helm CA, Müller R,

Staehlke S and Nebe JB (2020)

Enhancement of Intracellular Calcium Ion Mobilization by Moderately but Not Highly Positive Material Surface

Charges.

Front. Bioeng. Biotechnol. 8:1016. doi: 10.3389/fbioe.2020.01016
Electrostatic forces at the cell interface affect the nature of cell adhesion and function; but there is still limited knowledge about the impact of positive or negative surface charges on cell-material interactions in regenerative medicine. Titanium surfaces with a variety of zeta potentials between $-90 \mathrm{mV}$ and $+50 \mathrm{mV}$ were generated by functionalizing them with amino polymers, extracellular matrix proteins/peptide motifs and polyelectrolyte multilayers. A significant enhancement of intracellular calcium mobilization was achieved on surfaces with a moderately positive $(+1$ to $+10 \mathrm{mV})$ compared with a negative zeta potential $(-90$ to $-3 \mathrm{mV}$ ). Dramatic losses of cell activity (membrane integrity, viability, proliferation, calcium mobilization) were observed on surfaces with a highly positive zeta potential $(+50 \mathrm{mV})$. This systematic study indicates that cells do not prefer positive charges in general, merely moderately positive ones. The cell behavior of MG-63s could be correlated with the materials' zeta potential; but not with water contact angle or surface free energy. Our findings present new insights and provide an essential knowledge for future applications in dental and orthopedic surgery.

Keywords: human osteoblasts, calcium ion signaling, titanium surface modification, amino polymer, polyelectrolyte multilayer, zeta potential, surface charge, wettability

Abbreviations: AM, acetoxymethyl ester; APTES, (3-aminopropyl)triethoxysilan; ATP, adenosine 5' triphosphate; Col I, collagen-type I; Col IV, collagen-type IV; DAPI, 4',6-diamidino-2-phenylindole; DETA, (3-trimethoxysilylpropyl)diethylenetriamine; DMEM, Dulbecco's Modified Eagle Medium; DMSO, dimethyl sulfoxide; ECM, extracellular matrix; EDC, $N$-(3-dimethylaminopropyl)- $N$ '-ethylcarbodiimide hydrochloride; Ent, entactin; EthD- 1 , Ethidium Homodimer 1; HSPG, heparan sulfate proteoglycans; Lam, laminin; MES, 2-( $N$-morpholino) ethanesulfonic acid; $\mathrm{MFI}_{\mathrm{C}}$, mean fluorescence intensity of cells; $\mathrm{MFI}_{\mathrm{B}}$, basal mean fluorescence intensity; $\mathrm{MFI}_{\mathrm{A}}$, mean fluorescence intensity after ATP stimulation; MTS, 3-(4,5-dimethylthiazol-2-yl)-5-(3-carboxymethoxyphenyl)-2-(4-sulfophenyl)-2H-tetrazolium salt; NHS, N-hydroxysuccinimide; OeTS, 7-octenyltrichlorosilane solution; PAH, poly(allylamine hydrochloride); PAMAM, poly(amidoamine); PBS, phosphate buffered saline; PDADMA, poly(diallyldimethyl ammonium chloride); PEI, poly(ethylene imine); PEM, polyelectrolyte multilayer; PES, polyethersulfone; PFA, paraformaldehyde; PP, proliferative phase; PPAAm, plasma polymerized allylamine; PPI-G4, poly(propylene imine) dendrimer generation 4; PSS, poly(styrene sulfonate); RGD, peptide sequence Arg-Gly-Asp; ROI, region of interest; ROS, reactive oxygen species; RT, room temperature; SAM, self-assembled monolayer; SEM, scanning electron microscope; SFE, surface free energy; SPDP, $\mathrm{N}$-succinimidyl-3(2-pyridyldithio) propionate; TESPSA, 3-(triethoxysilyl)propyl succinic acid anhydride; Ti, titanium; WCA, water contact angle; XPS, X-ray photoelectron spectroscopy; $\zeta$, zeta potential. 


\section{INTRODUCTION}

Bone defects due to fractures, infections or tumor resections are one of the main causes of disability in an aging society, leading to a loss of quality of life (Akter and Ibanez, 2016). In orthopedic applications, titanium (Ti) has been and still is the material of choice due to properties such as high strength and corrosion resistance (Hanawa, 2019). To improve the bioactivity of Ti-based materials, several strategies are used, including physical treatments to modify the topography (Wennerberg and Albrektsson, 2009; Nikkhah et al., 2012; Kumar et al., 2019) or chemical treatments to modify the bioactivity (Kokubo and Yamaguchi, 2015; Muderrisoglu et al., 2018; Devgan and Sidhu, 2019) all aiming to optimize the interaction with osteoblastic cells.

Surface properties are one of the main factors influencing the cells' fate by guiding cellular processes at the interface from the very beginning (Felgueiras et al., 2018; Ferrari et al., 2019). As a result, the advanced cell-material interaction is a pivotal step determining the success of osseointegration, ultimately, the success of implants. Initial processes driven by the surface properties involve cellular attachment, adhesion and spreading (von der Mark and Park, 2013), which further affect other cell activities such as proliferation, differentiation (Bacakova et al., 2011), and intracellular signaling (Anselme et al., 2010; Staehlke et al., 2015, 2018). Stimulating cellular behavior at the interface by acting on surface physico-chemical properties, especially roughness, stiffness, wettability, and surface charge via surface functionalization can be an effective way to improve bone regeneration (Ferrari et al., 2019).

Previous research has shown that osteoblasts favor a certain range of roughness, pore size, wettability, specific biomacromolecules or their biomimetic motifs (Chen et al., 2018) and also stiffness (Abalymov et al., 2020). It could be demonstrated that cells prefer moderately hydrophilic surfaces displaying contact angles between $40^{\circ}$ and $65^{\circ}$ (Bacakova et al., 2011; Rebl et al., 2012; Mörke et al., 2017). However, other studies have shown that this is not always the case; for instance MG-63 osteoblasts exhibited increased cell attachment and spreading on methylated silicon surfaces with decreasing wettability (PadialMolina et al., 2011). Similarly, Kennedy et al. (2006) reported that MC3T3-E1 cells displayed improved cell proliferation with increased hydrophobicity and the lowest spreading on the most hydrophilic SAM (self-assembled monolayers) surface. Thus, the contact angle is not a good predictor of cell behavior (Gentleman and Gentleman, 2014).

Furthermore, it has been proven that extracellular matrix (ECM) proteins (mainly collagen, fibronectin, laminin and vitronectin) (Müller et al., 2006; Rico et al., 2009; Chen et al., 2018), their RGD sequence (Arg-Gly-Asp) (Mörke et al., 2017) and cytokines [e.g., basic fibroblast growth factor (bFGF)] (Cao et al., 2015) have the capacity to promote cell attachment.

Some explanations have also been suggested for the surface charge and its effect on the cell-material interaction. Surface charges can generate electrical cues necessary to regulate cell function (De Aza et al., 2003; Finke et al., 2007; FernándezYagüe et al., 2019). As human osteoblasts are negatively charged
(Rebl et al., 2016), positive surface charges significantly influence cell adhesion (Rebl et al., 2010; Dhowre et al., 2015; Mörke et al., 2017), spreading and proliferation (Staehlke et al., 2019), particularly in the early stages of cell responses. The most detailed study on the effect of surface charges to date is that of Metwally and Stachewicz (2019), indicating a great importance in the development of functionally implantable biomaterials. They reviewed that surface charges determine protein adsorption and thus the subsequent cell adhesion process. Referring to Goldenberg and Steinberg (2010) surface charge seems to be also important for the correct protein localization of signaling molecules in the cell membrane; it has been documented that proteins like GTPases of the Ras, Rho, Arf, and Rab protein families target the plasma membrane through electrostatic interactions (Heo et al., 2006).

The measurement of zeta $(\zeta)$ potentials is a suitable technique for characterizing the charging behavior at the solid-liquid interface of modified biomaterial surfaces (Ferraris et al., 2018). There are few papers that address materials such as hydrogels (Schulz et al., 2018), polyelectrolyte multilayers (PEM) (Guo et al., 2018) or metals (Ponsonnet et al., 2003; Nebe et al., 2007) exhibiting a positive $\zeta$-potential enhancing cell processes like cell adhesion, spreading, viability and proliferation. And yet present understanding of the mechanism involved in controlling cell activities via surface charge in tissue engineering is still limited.

In order to gain deeper insights into the impact of surface charges on the cell-material interaction, systematic experiments are required. Our previous work has shown that a plasma polymerized nanolayer of allylamine (PPAAm) provides positive charges on an otherwise negatively charged Ti surface that can boost cell behavior (reviewed in Nebe et al., 2019). The question arose whether a positive $\zeta$-potential is generally considered to be a decisive factor for the cellular outcome.

In the present study, we generated a broad range of surface charges to investigate in detail their influence on osteoblastic cell response via intracellular calcium ion $\left(\mathrm{Ca}^{2+}\right)$ mobilization, cell viability and proliferation. For this purpose, we deposited nine different top layers on $\mathrm{Ti}$ substrates from the following three categories: (i) amino polymers, (ii) ECM/peptide motifs, and (iii) PEM. We determined the physico-chemical characterization of these surfaces via water contact angles (WCA), surface free energies (SFE), X-ray photoelectron spectroscopy (XPS) and layer thicknesses, and employed $\zeta$-potential measurements to determine surface charges.

We hypothesize that cell physiology can be improved by material surfaces featuring a certain range of positive $\zeta$-potential.

\section{MATERIALS AND METHODS}

\section{Functionalization of Titanium Arrays}

The following section describes the methods for the diverse Ti surface modifications used for surface charge determination and in the cell biological experiments shown in Figure 1. They are categorized in modifications with amino polymers, ECM/peptide motifs, as well as in PEM. As base material and negative control we used planar silicon arrays sputtered 


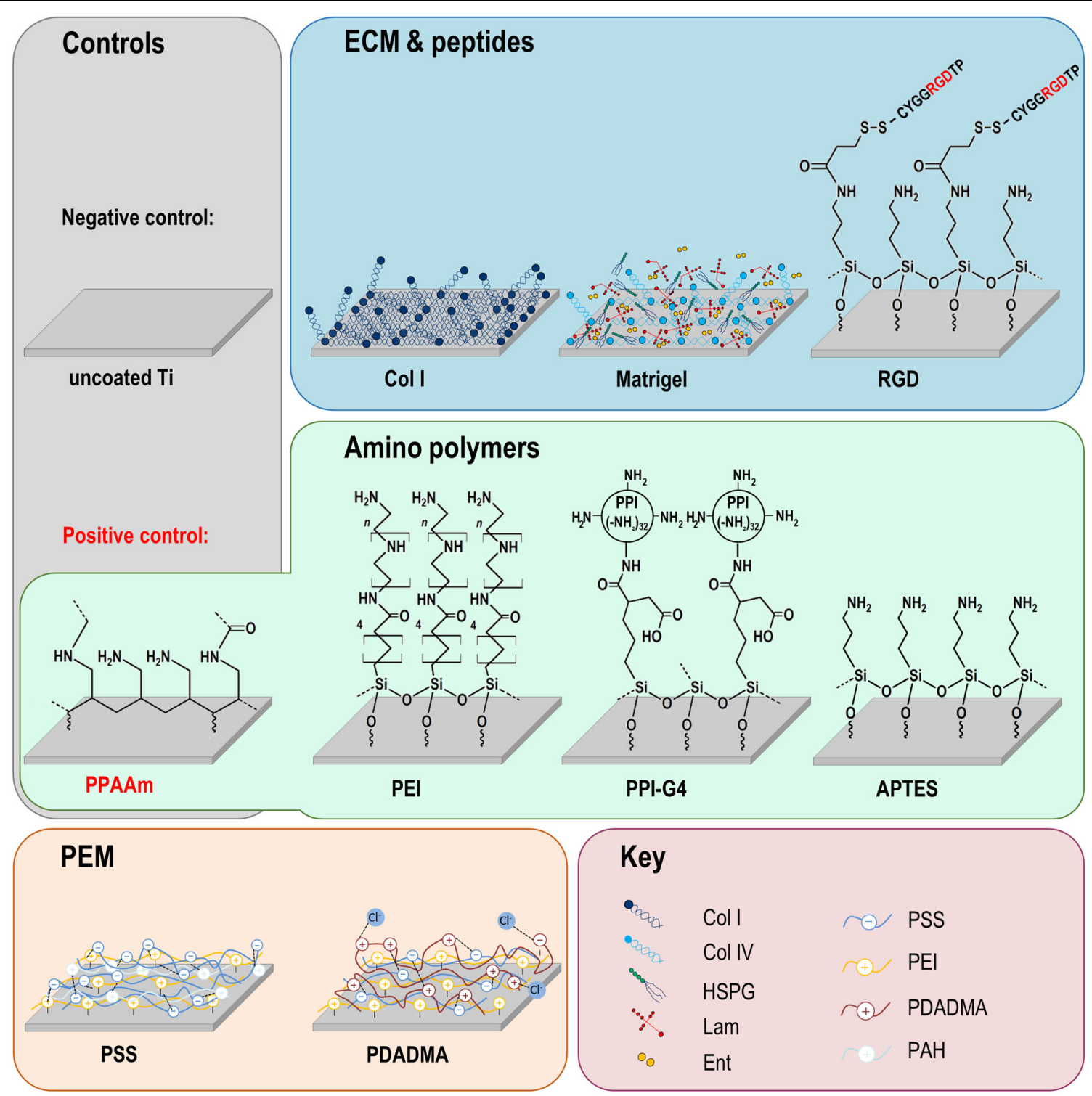

FIGURE 1 | Chemical surface modifications of plane Ti arrays. The modifications can be classified into three groups: amino polymers, extracellular matrix (ECM)/peptide motifs and polyelectrolyte multilayers (PEM). Please note that the molecular structures are schematic formula drawings (created using the freeware ACD/ChemSkretch 2018.2.5, Advanced Chemistry Development, Toronto, ON, Canada), which do not necessarily allow conclusions about the molecular length of the individual layers. Ti, titanium; Col I, collagen-type I; RGD, peptide sequence Arg-Gly-Asp; PPAAm, plasma polymerized allylamine; PEI, poly(ethylene imine); PPI-G4, poly(propylene imine) dendrimer generation 4; APTES, (3-aminopropyl)triethoxysilan; PSS, poly(styrene sulfonate); PDADMA, poly(diallyldimethylammonium chloride); HSPG, heparan sulfate proteoglycans; Lam, laminin; Ent, entactin; Col IV, collagen-type IV; PAH, poly(allylamine hydrochloride).

with $100 \mathrm{~nm} \mathrm{Ti}$ particles obtained from the Center for Microtechnologies (ZFM, University of Technology Chemnitz, Germany) at $1 \times 1 \times 0.075 \mathrm{~cm}$ in size (length $\times$ width $\times$ depth) for cell analysis, or $2 \times 1 \times 0.075 \mathrm{~cm}$ for $\zeta$-potential analysis as previously reported (Staehlke et al., 2018).

\section{Amino Polymers}

\section{Plasma polymerized allylamine (PPAAm)}

As it is known that the positively charged plasma polymerized allylamine (PPAAm) layer can improve several cell functions (Rebl et al., 2012; Mörke et al., 2017; Staehlke et al., 2018;
Nebe et al., 2019), this plasma functionalization of $\mathrm{Ti}$ was used as a positive control in all experiments. The specimens were coated with the PPAAm nanolayer by using a lowpressure plasma reactor (V55G, Plasma Finish, Germany) (Rebl et al., 2012) with the following parameters: continuous wave oxygen/argon plasma $\left(500 \mathrm{~W}, 50 \mathrm{~Pa}, 1000-\mathrm{sccm} \mathrm{O}_{2}, 5 \mathrm{sccm}\right.$ Ar, 60 s), 480 s PPAAm deposition time. PPAAm films have proven to be very robust according to DIN EN 582 (1993), mechanically stable (Fritsche et al., 2009) and can be used for cell experiments for up to 200 days when stored in ambient air (Finke et al., 2014). 


\section{(3-Aminopropyl)triethoxysilane (APTES)}

$\mathrm{Ti}$ surfaces were modified with the linker (3aminopropyl)triethoxysilane (APTES) (Mörke et al., 2017). Prior to modification, the substrates were cleaned and preactivated by water vapor plasma treatment for $15 \mathrm{~s}$ at $0.1 \mathrm{mbar}$ in a microwave. Then, Ti surfaces were coated with $100 \mathrm{mM}$ APTES (abcr, Karlsruhe, Germany) in toluene (Alfa Aesar/Fisher Scientific, Kandel, Germany) for $3 \mathrm{~h}$ at $60^{\circ} \mathrm{C}$ in an incubator (GFL 3032, Burgwedel, Germany) turning at $35 \mathrm{rpm}$. After carefully washing with ultrapure water, the samples were dried under a stream of pure nitrogen (ultra-high purity 5.0 grade) in a laminar flow box (Herasafe KS 12, Kendro, Langenselbold, Germany). APTES layers are stable up to 1 year when stored under exclusion of light and oxygen.

\section{Poly(ethylene imine) (PEI)}

Before functionalization, contaminants were removed from the substrate surface by sonicating in acetone (p.a., Sigma-Aldrich Chemie, Taufkirchen, Germany), followed by oxidation of the substrates in a semi-concentrated $\mathrm{HNO}_{3}$ solution $(38 \%, 1: 1 \mathrm{v} / \mathrm{v}$ from concentrated ( $\geq 65 \%)$ nitric acid, obtained from Carl Roth, Karlsruhe, Germany) for 1 week. The wafers were rinsed with ultrapure and sterile water multiple times until a neutral $\mathrm{pH}$ was obtained, then dried in a vacuum desiccator (Carl Roth). As described in previous publications, further modification steps were performed under an argon atmosphere in anhydrous solvents (dried with a molecular sieve from Carl Roth) (Eichler et al., 2011; Katzur et al., 2012). The synthesis of carboxylic acidterminated SAM (SAM-COOH) is based on the protocol by Liu et al. (2002) and was described previously (Katzur et al., 2012). Here, the silanization in a 7-octenyltrichlorosilane solution was carried out for $2 \mathrm{~h}$, the conversion of the terminal alkene groups in a $\mathrm{KMnO}_{4}$ solution for $15 \mathrm{~min}$.

For the immobilization of the poly(ethylene imine) (PEI) polymer, the SAM-COOH-modified substrates were first activated via immersion in a solution containing $100 \mathrm{mmol} / \mathrm{l} \mathrm{N}$ (3-dimethylaminopropyl)- $N$ '-ethylcarbodiimide hydrochloride (EDC) and $100 \mathrm{mmol} / \mathrm{l} \mathrm{N}$-hydroxysuccinimide (NHS) in $0.1 \mathrm{~mol} / \mathrm{l} 2$-(N-morpholino) ethanesulfonic acid (sodium salt) (MES) buffer (pH adjusted to 5.4) for $2 \mathrm{~h}$ at room temperature (RT). EDC, NHS and MES were purchased from Sigma-Aldrich Chemie of analytical grade. After rinsing once with MES buffer, twice with water and once with methanol (p.a., Fischer Scientific, Schwerte, Germany), the immobilization of the polymer was carried out in a $10 \mathrm{mg} / \mathrm{ml}$ PEI solution (linear, $\mathrm{Mw}=25 \mathrm{kDa}$, abcr, Karlsruhe, Germany) in a methanol/water mixture (9:1 v/v) for $1.5 \mathrm{~h}$ at RT. Excess polymer was removed by rinsing twice with the methanol/water mixture and once with methanol before the specimens were dried in a desiccator. PEI layers are stable for up to 8 weeks when stored in the dark and under argon atmosphere.

\section{Poly(propylene imine) dendrimer (PPI-G4)}

In respect to the functionalization with PEI described above, the surfaces were first cleaned by sonication and then oxidized for 1 week. Then a silanization of substrates with 3(triethoxysilyl)propyl succinic acid anhydride (TESPSA, abcr,
Karlsruhe, Germany) was performed according to previously published protocols (Eichler et al., 2011) at elevated temperatures $\left(110^{\circ} \mathrm{C}\right.$ for $30 \mathrm{~min}$, followed by $130^{\circ} \mathrm{C}$ for $10 \mathrm{~min}$ ) under an argon atmosphere. Excess silane was removed by rinsing twice with dry toluene. The specimens were sonicated once with dry dimethyl sulfoxide (DMSO, Fisher Scientific, Schwerte, Germany) and immersed in a $0.5 \mathrm{mmol} / \mathrm{l}$ poly(propylene imine) dendrimer generation 4 (PPI-G4, SyMO-Chem, Eindhoven, Netherlands) solution in anhydrous DMSO. The reaction was performed for at least $40 \mathrm{~h}$ at RT. Rinsing was performed by sonicating once with DMSO and at least three times with methanol before drying the wafers in a desiccator. PPI-G4 layers are stable for up to 8 weeks when stored in the dark and under argon atmosphere.

\section{Extracellular Matrix (ECM) Proteins and Peptide Motifs \\ Collagen type-I (Col I)}

Ti substrates were chemically wet-coated with $40 \mu \mathrm{g} / \mathrm{cm}^{2}$ collagen type-I (Col I; rat tail, Corning, Discovery Labware, Bedford, MA, United States) and dried overnight at RT (Rebl et al., 2010). Residues of acetic acid were removed by rinsing twice with sterile ultrapure water. Col I coatings were produced prior to cell experiments and used directly.

\section{Basement membrane matrix (Matrigel)}

Ti arrays were coated with basement membrane matrix (Matrigel) containing laminin, collagen type-IV, heparan sulfate proteoglycans, entactin and growth factors (Corning, Discovery Labware, Bedford, MA, United States) using a thin-film coating method. For this purpose, Matrigel was thawed on ice and diluted to a concentration of $1 \mathrm{mg} / \mathrm{ml}$ using serum-free ice-cold Dulbecco's Modified Eagle Medium (DMEM, 21063-029, Life Technologies Limited, Paisley, United Kingdom). $200 \mu \mathrm{l}$ of the solution was added to the Ti substrates $\left(200 \mu \mathrm{g} / \mathrm{cm}^{2}\right)$ with precooled pipette tips and incubated at RT for $1 \mathrm{~h}$ under sterile conditions. Unbound material was aspirated and substrates were rinsed gently using serum-free DMEM. Matrigel coatings were produced prior to cell experiments and used directly.

\section{Arginine-glycine-aspartic sequence (RGD)}

$\mathrm{Ti}$ surfaces were modified with a nonapeptide containing the arginine-glycine-aspartic acid (RGD)-tripeptide (complete amino acid sequence C-Y-G-G-R-G-D-T-P, kindly provided by Dr. K. Rischka, Fraunhofer IFAM Institute Bremen, Germany) as reported in Mörke et al. (2017). Prior to peptide coupling Ti substrates was coated with APTES as described above. RGD layers are stable up to 1 year when stored under exclusion of light and oxygen.

\section{Polyelectrolyte Multilayers (PEM)}

Polyelectrolyte multilayer films were created by dip-coating of oppositely charged polyelectrolytes with a deposition robot (Riegler \& Kirstein, Potsdam, Germany) according to Mohamad et al. (2019). Here, we used PEI [branched, $\mathrm{Mw}=750 \mathrm{kDa}$, polydispersity $(\mathrm{PDI})=12.5$ ], polyallylamine hydrochloride $(\mathrm{PAH}$, $\mathrm{Mw}=50-60 \mathrm{kDa}$ ) and poly (diallyldimethylammonium chloride) $($ PDADMA, $\mathrm{Mw}=322 \mathrm{kDa}, \mathrm{PDI}=2.19)$ as polycations and 
poly(styrene sulfonate) sodium salt (PSS, Mw = $666 \mathrm{kDa}$, PDI $<1.2)$ as polyanion.

PSS-terminated PEM consisted of three double layers with the sequence PEI/PSS/(PAH/PSS $)_{2}$. PDADMA-terminated polyelectrolyte brushes were composed of 10.5 double layers with the sequence PEI/PSS/(PDADMA/PSS) 9 /PDADMA. The layer stability of prepared PEM was verified by AFM measurements [DI Multimode AFM using NanoScope IIIa software from Veeco (Santa Barbara, CA, United States)]. Layers are stable in the range of $\mathrm{pH} 3-11$, in solutions up to $1 \mathrm{M} \mathrm{NaCl}$ and after storage in ambient air up to 1 year unchanged.

\section{Surface Characterization Zeta Potential}

$\zeta$-potentials were assessed with the SurPASS ${ }^{\mathrm{TM}}$ system (Anton Paar, Ostfildern, Germany) and the associated software Attract 2.1 as previously published (Staehlke et al., 2018). Streaming potentials were measured at $\mathrm{pH} 6.5-8.0$ in a $1 \mathrm{mM} \mathrm{KCl}$ solution (VWR International, Darmstadt, Germany) and $\zeta$-potentials at $\mathrm{pH} 7.4$ were calculated via a linear regression using the software GraphPad Prism version 6.05 ( $n=3$, three pairs of samples).

\section{Surface Wettability}

Surface free energies of the substrate/air interface and WCA were determined by the sessile drop method using the Drop Shape Analyzer-DSA25 (Krüss, Hamburg, Germany) (Staehlke et al., 2018). One $\mu 1$ drops of distilled water and diiodomethane (Sigma-Aldrich Chemie, Taufkirchen, Germany) were deposited on the sample surface ( $n=3$ at 3 drops each). WCA values were calculated with the supplied software (ADVANCE, V.1.7.2.1, Krüss, Hamburg, Germany) via the Young's equation and the SFE according to Owens, Wendt, Rabel und Kaelble (OWRK).

\section{Layer Thickness}

Layer thickness was measured with null ellipsometry (Multiskop; Optrel GbR, Sinzing, Germany) as described before (Mörke et al., 2017). Each sample was modeled by 6 slabs in order to account for oxide layers $\left(\mathrm{Si}, \mathrm{SiO}_{2}, \mathrm{Ti}, \mathrm{TiO}_{2}\right.$, layer of interest and ambient air). The thickness of the $\mathrm{Ti}$ and $\mathrm{TiO}_{2}$ layer was determined independently prior to deposition of the layer of interest. Additionally, uncoated samples were measured and served as a reference. Each measurement was carried out at several angles of incidence $\left(50^{\circ}-80^{\circ}\right.$ in $1^{\circ}$ steps $)$ in two different ellipsometric zones (Nestler et al., 2012).

\section{Chemical Composition}

The elemental composition of the modified surfaces was analyzed by using an AXIS Supra X-ray photoelectron spectrometer from Kratos Analytical Ltd. (Manchester, United Kingdom). Measurements were performed using a monochromatic Al Ka $\mathrm{X}$-ray source $(1486.6 \mathrm{eV})$ operated at $150 \mathrm{~W}$. Survey and corelevel spectra were acquired using a pass energy of $80 \mathrm{eV}$. For each sample, an area of $250 \mu \mathrm{m}$ was analyzed in duplicates on three different positions. During the analysis, the integrated charge neutralization system was activated for charge compensation. XPS measurements for PEI and PPI-G4 were performed with a PHI 5700 (Physical Electronics, United States). Here, survey and core-level spectra were acquired using pass energies of 117$187 \mathrm{eV}$. Charge neutralization was not necessary.

\section{Cell Biological Investigations Cell Culture}

Human osteoblast-like MG-63 cells (American Type Culture Collection ATCC ${ }^{\circledR}$, CRL1427 $^{\mathrm{TM}}$, Bethesda, MD, United States) were used; this cell line has been successfully applied as a model for studying cell-material interactions (Staehlke et al., 2019) and has similar characteristics to primary human osteoblasts (Clover and Gowen, 1994; Czekanska et al., 2014). The cells were cultured in Dulbecco's Modified Eagle Medium (DMEM, 31966-021, Life Technologies Limited, Paisley, United Kingdom), with $10 \%$ fetal calf serum (FCS, Biochrom FCS Superior, Merck, Darmstadt, Germany) and 1\% antibiotics (gentamicin, Ratiopharm, Ulm, Germany) at $37^{\circ} \mathrm{C}$ with $5 \% \mathrm{CO}_{2} / 95 \%$ air atmosphere (Staehlke et al., 2018). All experiments were performed in passages 5-30, as the MG-63 cell physiology is known to remain stable over the entire range of these passages (Staehlke et al., 2019).

\section{Cell Morphology}

Scanning electron microscopy (SEM)

MG-63s $\left(15,000\right.$ cells $\left./ \mathrm{cm}^{2}\right)$ were cultured for $24 \mathrm{~h}$ on the $\mathrm{Ti}$ arrays, washed three times with phosphate buffered saline (PBS, Sigma-Aldrich Chemie, Taufkirchen, Germany), fixed with 2.5\% glutardialdehyde (Merck, Darmstadt, Germany) at $4^{\circ} \mathrm{C}$ overnight and rinsed with $0.1 \%$ sodium phosphate buffer (according to Sørensen, Merck, Darmstadt, Germany). The samples were then dehydrated through an ethanol series of 30, 50, 75, 90 and twice $100 \%$ (for 5, 5, 15, 10, and $10 \mathrm{~min}$, respectively) and dried in a critical point dryer (K 850, EMITECH, Taunusstein, Germany). The samples were sputtered with gold for $50 \mathrm{~s}(15 \mathrm{~nm}, \mathrm{SCD}$ 004, BAL-TEC, Wetzlar, Germany) and field emission scanning electron microscopy (FE-SEM, ZEISS Merlin VP compact, Carl Zeiss, Oberkochen, Germany) observations were taken with an acceleration voltage of $5 \mathrm{kV}$, a working distance of $5.6 \mathrm{~mm}$ and a high efficiency secondary electron detector (InlenseDuo for 2,000x, HE-SE2 detector for 100, 500x, and 5,000x).

\section{Circularity}

The circularity of the cells after $24 \mathrm{~h}$ could be evaluated with Photoshop CC 2017 using fluorescence microscopic images of fluoro-3-acetoxymethyl ester (fluo-3) stained cells ( $n \geq 3$ independent experiments á 15 cells). These images were also used for determining the cell area as basic values for the $\mathrm{Ca}^{2+}$ mobilization experiments (Supplementary Table S1). For the staining procedure see section "Intracellular $\mathrm{Ca}^{2+}$ mobilization." A circularity value of 1.0 represents a perfect circle, whereas a value converging toward 0 indicates an elongated polygon.

\section{Cell Viability}

Cell viability was analyzed by an MTS assay, flow cytometry (both described in the Supplementary Material) and live/dead staining for selective surfaces representing negative, moderately and $2 \mathrm{x}$ highly positive surface charges (Ti, PPAAm, PPI-G4, and PDADMA, respectively). For live/dead staining a cell viability kit (L3224, Molecular Probes, Eugene, OR, United States) 
was used. This two-color fluorescence assay is based on the measurement of intracellular esterase activity of living cells (Calcein-acetoxymethyl ester, Calcein-AM) and the abrogation of the plasma membrane integrity of dead cells (Ethidium homodimer-1, EthD-1). While EthD-1 is excluded by the intact plasma membrane of living cells, it can enter cells with damaged cell membrane and binds to nucleic acids. After a cultivation period of $24 \mathrm{~h}$ MG-63s $\left(80,000\right.$ cells $\left./ \mathrm{cm}^{2}\right)$ were washed carefully with PBS and incubated with a CalceinAM/EthD-1 solution (1:1, $2 \mu \mathrm{M}$ Calcein-AM, $4 \mu \mathrm{M}$ EthD-1) for $20 \mathrm{~min}$ at $37^{\circ} \mathrm{C}$ in the dark. The cells were then rinsed with PBS and fixed with 4\% paraformaldehyde (PFA, Sigma-Aldrich Chemie, Taufkirchen, Germany) at RT for $10 \mathrm{~min}$. Samples were embedded on a coverslip with mounting medium Fluoroshield ${ }^{\mathrm{TM}}$ (Sigma-Aldrich Chemie, Taufkirchen, Germany) containing 4',6diamidino-2-phenylindole (DAPI) and examined using the confocal laser scanning microscope LSM780 (Carl Zeiss, Jena, Germany) with a Plan-Apochromat $63 x$ oil immersion objective (Carl Zeiss; zoom 1 and 2.5) and the ZEN software (ZEISS efficient navigation, ZEN 2011 SP4, black edition, Carl Zeiss).

\section{Intracellular $\mathrm{Ca}^{2+}$ Mobilization \\ Pre-screening study}

The $\mathrm{Ca}^{2+}$ mobilization process in MG-63s was specified with respect to the adenosine $5^{\prime}$-triphosphate (ATP) concentration for cell stimulation, $\mathrm{Ca}^{2+}$ origin and the presence of ATP receptors as provided in the Supplementary Material. The basal $\mathrm{Ca}^{2+}$ signal of MG-63s on Ti and PPAAm controls was validated by immunofluorescence. Therefore, $50,000 \mathrm{cells} / \mathrm{cm}^{2}$ were stained after $1 \mathrm{~h}$ with the $\mathrm{Ca}^{2+}$ indicator fluo-3 $(5 \mu \mathrm{M}$, Life Technologies Corporation, Eugene, OR, United States) (Staehlke et al., 2015, 2018), Hoechst 33342 (1:1000, Life Technologies Corporation) and for images after $24 \mathrm{~h}$ additionally with $20 \mu \mathrm{l}$ BacMam 2.0 reagent (CellLight ${ }^{\mathrm{TM}}$ actin-RFP, Life Technologies Corporation) at $37^{\circ} \mathrm{C}$ in isotonic $4-(2$ hydroxyethyl)-1-piperazineethanesulfonic acid buffer (HEPES) (Staehlke et al., 2015, 2018). Confocal laser scanning microscopy (LSM780, Carl Zeiss, Jena, Germany) was carried out with a PlanApochromat 63x oil immersion objective (Carl Zeiss, 1.40. Oil DIC M27) and the ZEN software (ZEISS efficient navigation, ZEN 2011 SP4, black edition, Carl Zeiss).

\section{$\mathrm{Ca}^{2+}$ mobilization}

$\mathrm{Ca}^{2+}$ mobilization experiments on different $\mathrm{Ti}$ surface modifications were performed according to Staehlke et al. $(2015,2018)$. In brief, 80,000 cells $/ \mathrm{cm}^{2}$ were seeded onto the samples for $24 \mathrm{~h}$ and then loaded with $5 \mu \mathrm{M}$ fluo-3 in $\mathrm{Ca}^{2+}$ containing HEPES buffer via a hypo-osmotic shock treatment. $\mathrm{Ca}^{2+}$ fluorescence signals of 10 single cells per surface over a time span of $480 \mathrm{~s}$ were recorded with a confocal laser scanning microscope LSM780 and the ZEN software (ZEN 2011 SP4, black edition) with the following settings: scan mode 'time series' (1 frame every $2 \mathrm{~s}, 240$ frames in total), maximum pinhole (15 airy unit, $13.5 \mu \mathrm{m}$ section), gain 632 , digital offset -3 . First, the basal $\mathrm{Ca}^{2+}$ signal was recorded for $180 \mathrm{~s}$. Then, the cells were stimulated with ATP $(0.5 \mathrm{mM}$, SERVA Electrophoresis, Heidelberg, Germany), which indicates the reactivity of vital cells in dependence of the underlying chemical layer. At least three independent experiments per modification with 10 cells each for 240 analysis points per cell were investigated $(=7,200$ records per surface modification). The mean fluorescence intensity of the single cells $\left(\mathrm{MFI}_{\mathrm{C}}\right)$ was evaluated with the ZEN2 software (blue edition, version 2.0.0.0, Carl Zeiss). For this purpose, ten defined boxes were positioned on randomly chosen cells in the first image of the time series (one box per cell). Using the function 'mean ROI' (region of interest), the software analyzed the MFI of the boxes $\left(\mathrm{MFI}_{\mathrm{ROI}}\right)$ for 240 time points per cell. However, the $\mathrm{MFI}_{\mathrm{ROI}}$ represents only a small sub-area of a cell (Supplementary Figure S4). Compared with a flat expanded cell, the $\mathrm{Ca}^{2+}$ signal of a spherical cell (more cell volume under limited area as cell height is larger) is concentrated on a smaller area, which leads to increased $\mathrm{MFI}_{\mathrm{ROI}}$ values. Therefore, the $\mathrm{MFI}_{\mathrm{ROI}}$ values were normalized to the mean area of cells after $24 \mathrm{~h}\left(\mathrm{~A}_{\mathrm{C}}\right)$ and the defined area of ROI ( $\left.\mathrm{A}_{\mathrm{ROI}}\right)$, assuming that $\mathrm{MFI}_{\mathrm{ROI}}$ is independent of the ROI position in the cell. Accordingly, the $\mathrm{A}_{\mathrm{C}}$ of 15 fluo-3 stained cells per surface were measured with the software Photoshop CC 2017 ( $n=3$ independent experiments, Supplementary Table S1). The $\mathrm{MFI}_{\mathrm{C}}$ is described in the form:

$$
M F I_{c}=M F I_{R O I} \times \frac{A_{c}}{A_{R O I}}
$$

where $\mathrm{MFI}_{\mathrm{C}}$ is the mean fluorescence intensity of cells at $0-480 \mathrm{~s}$, $\mathrm{MFI}_{\mathrm{ROI}}$ is the mean fluorescence intensity of the region of interest (ROI), $A_{C}$ is the mean area of cells after $24 \mathrm{~h}\left(\mu \mathrm{m}^{2}\right)$, and $A_{R O I}$ is the defined area of ROI $\left(100 \mu \mathrm{m}^{2}\right)$. To calculate the mean basal fluorescence intensity of a cell $\left(\mathrm{MFI}_{\mathrm{B}}\right), \mathrm{MFI}_{\mathrm{ROI}}$ values of $0-170 \mathrm{~s}$ were used. In order to determine the MFI after ATP stimulation $\left(\mathrm{MFI}_{\mathrm{A}}\right), \mathrm{MFI}_{\mathrm{ROI}}$ values of $190-240$ s were employed. The $\mathrm{Ca}^{2+}$ mobilization (increase of the $\mathrm{Ca}^{2+}$ signal = slope) was calculated by subtracting the $\mathrm{MFI}_{\mathrm{B}}$ from $\mathrm{MFI}_{\mathrm{A}}$.

\section{Statistics}

Non-parametric Kruskal-Wallis followed by Dunn's multiple comparisons test (or non-parametric Wilcoxon matched pairs signed-rank test) with the software GraphPad Prism version 6.05 for Windows (GraphPad Software, La Jolla, CA, United States) was conducted on the $p$-values $<0.05$. Results are presented in (i) mean \pm sem (standard error of the mean) for $\mathrm{MFI}_{\mathrm{C}}$ values of the $\mathrm{Ca}^{2+}$ mobilization, (ii) in mean $\pm \mathrm{SD}$ (standard deviation) for proliferation and cell area values, as well as for WCA, SFE, $\zeta$-potential and XPS analyses, and (iii) in median with interquartile ranges (IQR) for cell circularity and MTS values.

\section{RESULTS}

\section{Physico-Chemical Characterization of $\mathrm{Ti}$ Surface Coatings}

Results regarding layer thickness, wettability and surface charge (deduced from $\zeta$-potentials) are given in Table 1. The chemical surface composition determined by XPS measurements is listed in Supplementary Table S2. 
TABLE 1 | Surface characteristics of chemically modified Ti (mean $\pm \mathrm{SD}, n=3$ ).

\begin{tabular}{|c|c|c|c|c|c|}
\hline Surface & & Layer thickness [nm] & WCA $\left[^{\circ}\right]$ & $\begin{array}{c}\text { SFE }[\mathrm{mN} / \mathrm{m}] \\
\text { dispersive } \\
\text { polar }\end{array}$ & $\zeta$ at $\mathrm{pH} 7.4[\mathrm{mV}]$ \\
\hline \multirow[t]{6}{*}{ Controls } & $\mathrm{Ti}$ & $9.0+\mathrm{TiO}_{2}(5.0)$ & $87.4 \pm 0.8$ & $37.6 \pm 1.4$ & $-87.5 \pm 1.6$ \\
\hline & & & & $35.6 \pm 1.1$ & \\
\hline & & & & $2.1 \pm 0.3$ & \\
\hline & PPAAm & 24.5 & $66.9 \pm 1.7$ & $46.2 \pm 1.5$ & $+7.1 \pm 2.7$ \\
\hline & & & & $36.2 \pm 0.6$ & \\
\hline & & & & $10.0 \pm 1.0$ & \\
\hline \multirow[t]{9}{*}{ Amino Polymers } & APTES & 5.0 & $88.1 \pm 4.1$ & $37.0 \pm 2.7$ & $+1.9 \pm 1.5$ \\
\hline & & & & $35.1 \pm 1.6$ & \\
\hline & & & & $1.9 \pm 1.0$ & \\
\hline & PEI & 18.0 & $27.6 \pm 2.4$ & $74.3 \pm 2.1$ & $+9.1 \pm 2.6$ \\
\hline & & & & $48.8 \pm 0.9$ & \\
\hline & & & & $25.5 \pm 1.1$ & \\
\hline & PPI-G4 & 23.0 & $47.2 \pm 4.3$ & $62.4 \pm 3.6$ & $+50.2 \pm 6.2$ \\
\hline & & & & $45.0 \pm 1.2$ & \\
\hline & & & & $17.4 \pm 2.4$ & \\
\hline \multirow[t]{9}{*}{ ECM and Peptides } & Col I & 165.0 & $50.5 \pm 4.3$ & $58.6 \pm 3.5$ & $-2.8 \pm 1.5$ \\
\hline & & & & $41.6 \pm 1.1$ & \\
\hline & & & & $17.0 \pm 2.5$ & \\
\hline & Matrigel & 5.5 & $69.6 \pm 6.9$ & $46.7 \pm 5.4$ & $-43.3 \pm 1.0$ \\
\hline & & & & $38.9 \pm 2.1$ & \\
\hline & & & & $7.8 \pm 3.3$ & \\
\hline & RGD & 5.6 & $74.9 \pm 1.2$ & $43.0 \pm 1.8$ & $+1.7 \pm 1.0$ \\
\hline & & & & $37.0 \pm 1.2$ & \\
\hline & & & & $6.0 \pm 0.6$ & \\
\hline \multirow[t]{6}{*}{ Polyelectrolyte Multilayers } & PSS & 7.0 & $62.3 \pm 2.7$ & $49.3 \pm 2.3$ & $-88.8 \pm 11.8$ \\
\hline & & & & $37.2 \pm 0.8$ & \\
\hline & & & & $12.1 \pm 1.5$ & \\
\hline & PDADMA & 38.0 & $38.7 \pm 3.2$ & $62.0 \pm 3.3$ & $+51.4 \pm 3.6$ \\
\hline & & & & $34.6 \pm 1.3$ & \\
\hline & & & & $27.3 \pm 2.0$ & \\
\hline
\end{tabular}

\section{Layer Thickness}

The layer thickness of all modifications was less than or equal to $165 \mathrm{~nm}$. The oxide layer of titanium surfaces was found to be $5 \mathrm{~nm}$. The thinnest layer was achieved with RGD $(0.6 \mathrm{~nm})$ with an underlying APTES layer of $5.0 \mathrm{~nm}$ (in total $5.6 \mathrm{~nm}$ ). The thickest layer was measured for $\mathrm{Col} \mathrm{I}$ at $165 \mathrm{~nm}$.

\section{Wettability}

The analysis demonstrated a change to more hydrophilic surfaces for all modifications except APTES, indicated by a decrease in WCA and an increase in SFE. Uncoated Ti surfaces as well as APTES-functionalized surfaces showed the highest WCA (with Ti $87.4^{\circ}<$ APTES $88.1^{\circ}$ ), the lowest SFE under $40 \mathrm{mN} / \mathrm{m}$ and the lowest content of polar interactions with $\leq 2 \mathrm{mN} / \mathrm{m}$. PEI-functionalized surfaces displayed the lowest WCA $\left(27.6^{\circ}\right)$ and consequently were the most hydrophilic surfaces showing the highest SFE values $(74.3 \mathrm{mN} / \mathrm{m})$ with polar interactions of $25.5 \mathrm{mN} / \mathrm{m}$.

\section{Zeta Potential}

A less negative $\zeta$-potential was achieved on almost all surfaces compared with uncoated $\mathrm{Ti}$ at $-87.5 \mathrm{mV}$. Only the $\zeta$-potential of PSS $(-88.8 \mathrm{mV})$ was slightly lower. Further negative surface potentials were found for Matrigel $(-43.3 \mathrm{mV})$. Col I substrates exhibit only a slightly negative $\zeta$-potential $(-2.8 \mathrm{mV})$. All other surfaces present a positive $\zeta$-potential and can be classified as moderately and highly positive. Moderately positively charged surfaces include PPAAm, APTES, PEI and RGD $(+7.1,+1.9,+9.1$, and $+1.7 \mathrm{mV}$, respectively), whereas highly positively charged surfaces comprise PPIG4 and PDADMA (+50.2 and $+51.4 \mathrm{mV}$, respectively). Here we sorted the investigated surfaces starting with the most negative $\zeta$-potential: PSS $<\mathrm{Ti}<$ Matrigel $<$ Col I $<$ RGD $<$ APTES $<$ PPAAm $<$ PEI $<$ PPI-G4 $<$ PDADMA.

\section{Cell Biological Investigations}

The effect of positive and negative $\zeta$-potential of chemically modified $\mathrm{Ti}$ surfaces on MG-63s behavior was observed and correlated.

\section{Cell Morphology}

The cell morphology on highly positively charged PPI-G4 and PDADMA surfaces was significantly changed to a more round shape (circularity 0.74 and 0.77 , respectively) compared to 


\begin{tabular}{|c|c|c|c|c|c|c|c|c|c|c|c|c|}
\hline \multirow[t]{4}{*}{ A } & 론 & Surface & $\mathrm{Ti}$ & PPAAm & APTES & PEI & PPI-G4 & Col I & Matrigel & RGD & PSS & PDADMA \\
\hline & $\overline{5}$ & Median & 0.36 & 0.44 & 0.45 & 0.38 & 0.74 * & 0.37 & 0.50 & 0.46 & 0.50 & $0.77^{*}$ \\
\hline & 온 & $25^{\text {th }}$ Quartile & 0.28 & 0.37 & 0.36 & 0.32 & 0.67 & 0.26 & 0.38 & 0.40 & 0.36 & 0.74 \\
\hline & $\bar{c}$ & $75^{\text {th }}$ Quartile & 0.45 & 0.54 & 0.66 & 0.49 & 0.77 & 0.50 & 0.65 & 0.64 & 0.57 & 0.81 \\
\hline
\end{tabular}

B
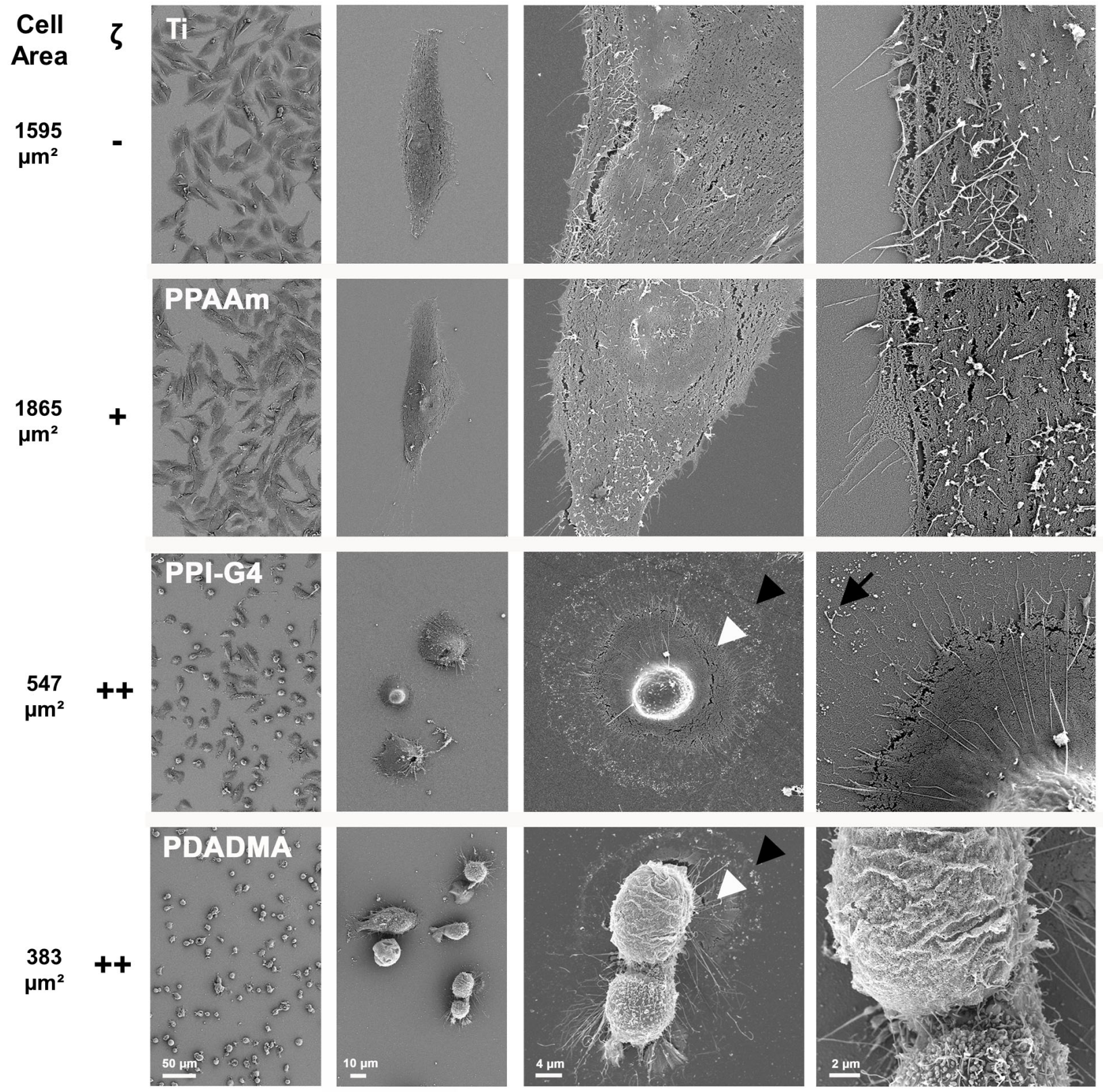

FIGURE 2 | Morphology of MG-63s after $24 \mathrm{~h}$ on bare and functionalized Ti with negative (-), moderately positive (+) and highly positive (++) $\zeta$-potential. (A) The cell circularity on highly positive surface charges reveals a morphologically significant difference to the other surfaces $\left(^{*}\right)$. A circularity value of 1.0 represents a perfect circle. (Statistics: Kruskal-Wallis and Dunn's multiple comparison test, ${ }^{*} p<0.05$; median $\pm I Q R ; n=3$ independent experiments). (B) Note the enormous decrease in cell area (from black arrowhead to white) on PPI-G4 and PDADMA. The PPI-G4 image (right) shows filopodia residues after the cell has retracted (arrow). On PDADMA different membrane structures with and without microvilli are visible (right image). (SEM images, magnification from left to right 100, 500, 2,000 and 5,000x, scale bars 50, 10, 4, and $2 \mu \mathrm{m}$, respectively, FE-SEM Merlin VP compact; mean cell area, $n=3$ independent approaches, fluo-3 staining, LSM780). 

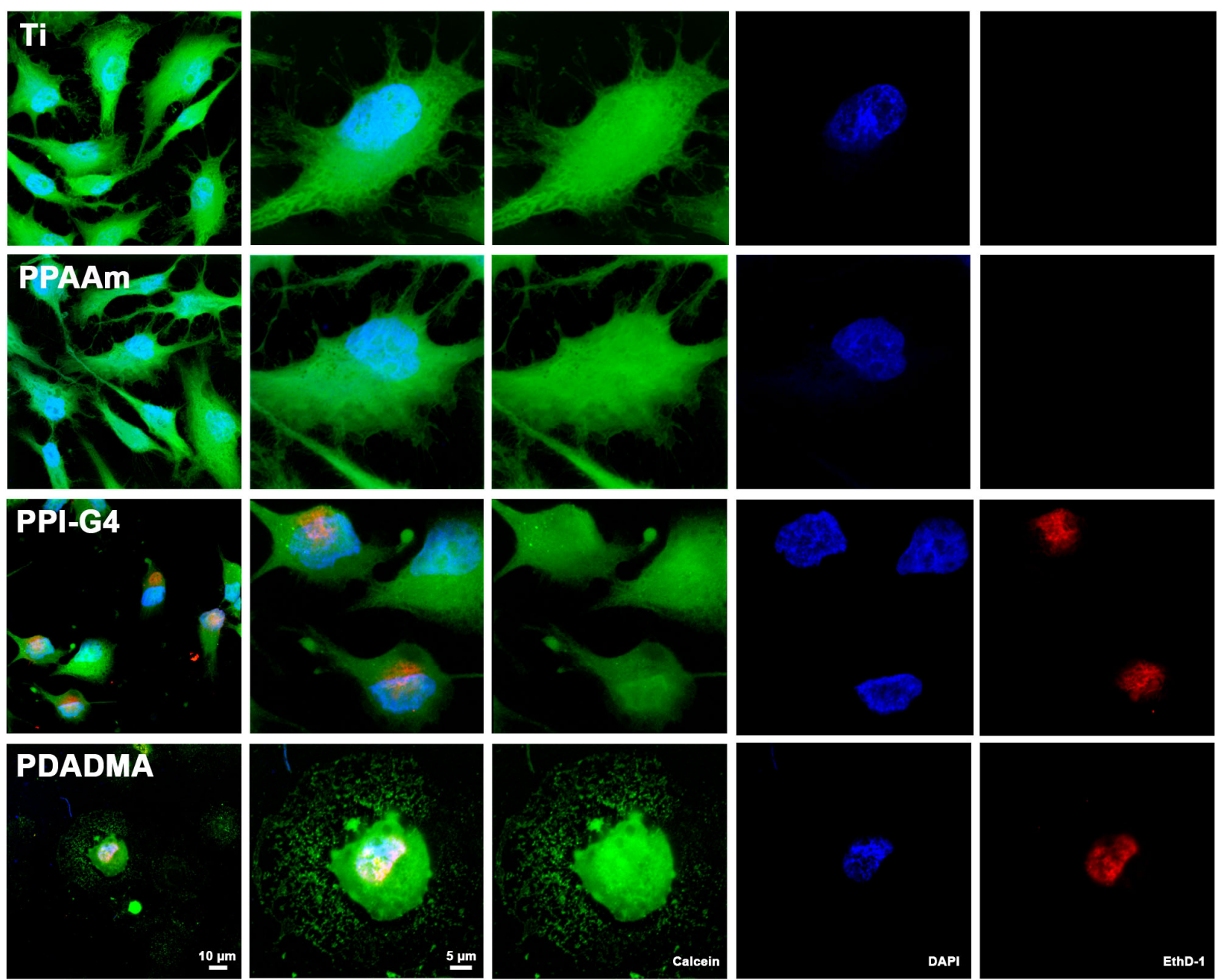

FIGURE 3 | Cell viability of MG-63s after $24 \mathrm{~h}$ on Ti and PPAAm arrays representing negatively and moderately positive surface charges, as well as PPI-G4 and PDADMA, representing highly positive surface charges. Cells on PPI-G4 and PDADMA surfaces are stained with both calcein and EthD-1, indicating damaged plasma membranes. (Immunofluorescence images of live/dead staining; $63 x$ objective with $1 \times$ and $2.5 x$ zoom, scale bar 10 and $5 \mu$ m; nucleus in blue (DAPI), esterase activity of living cells in green (calcein), DNA of cells with abrogated membrane integrity in red (EthD-1); LSM780).

all other surfaces with a polygonal shape (Figure 2A). High resolution SEM images revealed a decrease in cell area of MG-63s on PPI-G4 and PDADMA (Figure 2B, indicated by arrowheads), showing impaired cell morphology in contrast to well spread phenotypes on Ti and PPAAm. At 5,000x magnification, filopodia and membrane residues of cells on PPI-G4 are visible (arrow), whereas cells on PDADMA also show an altered membrane structure, as no microvilli are presented in individual cells.

\section{Cell Viability}

Fluorescence live/dead images displayed several cells on highly positively charged PPI-G4 and PDADMA surfaces that were positive for both Calcein and EthD-1 in contrast to $\mathrm{Ti}$ and PPAAm, suggesting a damaged plasma membrane (Figure 3). These images also confirmed the reduced cell area and circular shape on PPI-G4 and PDADMA after $24 \mathrm{~h}$. In addition, we observed a decreased relative cell viability (Supplementary Figure S1) and cell proliferation (Supplementary Figure S2) on these surfaces compared with Ti and PPAAm, with a greater extent on PDADMA surfaces. While the amount of proliferative cells declined (with 64.1, 66.8, 51.8, and $24.6 \%$ for Ti, PPAAm, PPI-G4 and PDADMA, respectively), the cells increasingly remained in the $\mathrm{G} 1$ phase $(34.0,32.2,47.5$, and $73.7 \%$ for $\mathrm{Ti}$, PPAAm, PPI-G4 and PDADMA, respectively).

\section{Intracellular $\mathrm{Ca}^{2+}$ Mobilization}

The intracellular basal $\mathrm{Ca}^{2+}$ signals on the control surfaces Ti and PPAAm are depicted in Figure 4. The fluorescence images reveal an increased cell area on PPAAm after $1 \mathrm{~h}$ compared with the uncoated Ti control (white dotted lines), while cells are equally spread after $24 \mathrm{~h}$ (insert top right). The basal $\mathrm{Ca}^{2+}$ level was found elevated after $1 \mathrm{~h}$ as well as after $24 \mathrm{~h}$ on PPAAm compared with Ti. Consequently, these control surfaces were consistently included in the following $\mathrm{Ca}^{2+}$ mobilization experiments.

The influence of the individual $\mathrm{Ti}$ modifications on $\mathrm{Ca}^{2+}$ mobilization in vital cells is presented in Figure 5 (an overview 

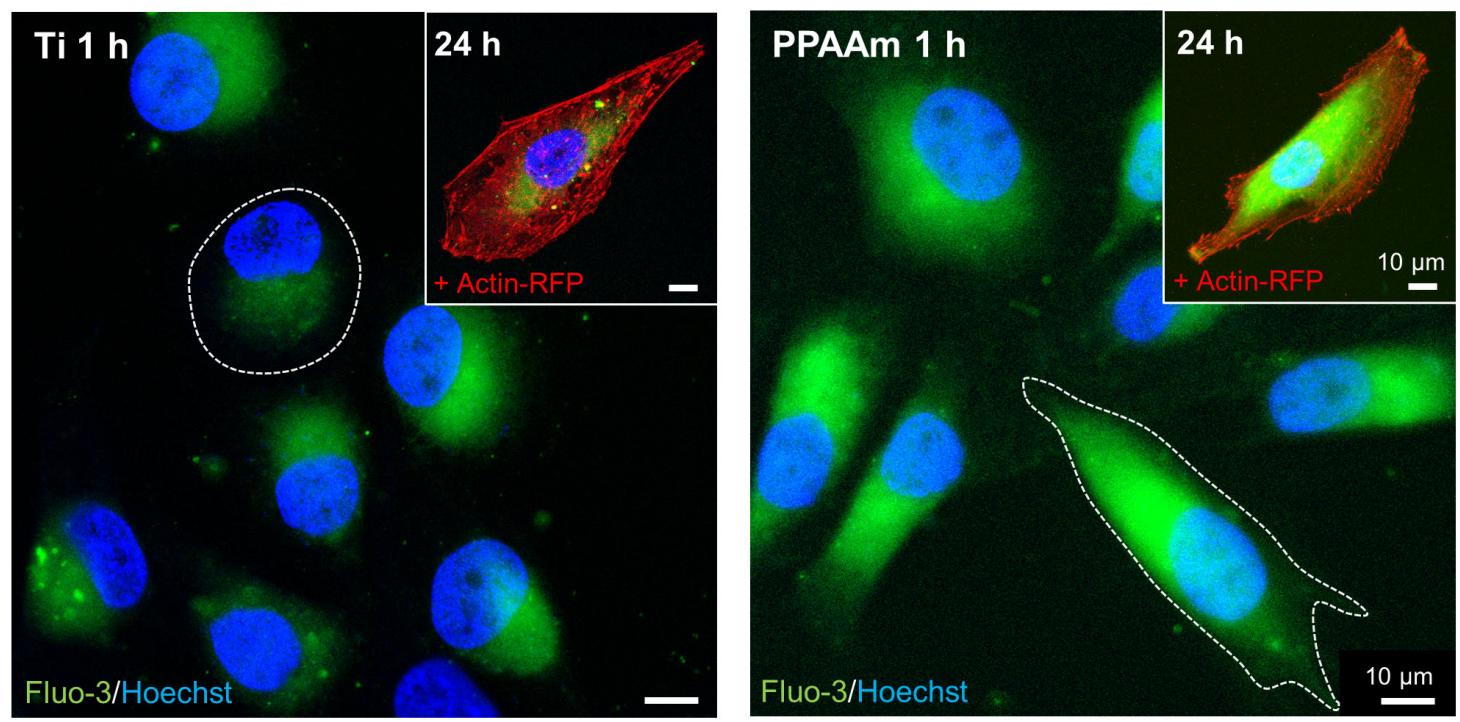

FIGURE 4 | Basal Ca ${ }^{2+}$ signals in living MG-63s after $1 \mathrm{~h}$ and $24 \mathrm{~h}$ on the control surfaces Ti (left) and PPAAm (right). The intracellular basal Ca ${ }^{2+}$ level on PPAAm is increased both after 1 and $24 \mathrm{~h}$, suggesting higher cell function. While cells on PPAAm exhibit a larger cell area after $1 \mathrm{~h}$ (white dotted line), the area is balanced after 24 h. (Immunofluorescence images; 63x objective, scale bar $10 \mu \mathrm{m}$; nucleus in blue (Hoechst), Ca ${ }^{2+}$ ions in green (fluo-3), cytoskeleton in red (actin-RFP); LSM780).

of the time series with fluorescence images can be found in the Supplementary Figure S5). Shown are the whole time series of $\mathrm{Ca}^{2+}$ mobilization in MG-63 osteoblasts cultured $24 \mathrm{~h}$ on Ti modifications (blue curves) and the corresponding controls (gray curves $=\mathrm{Ti}$, green $/$ red curves $=$ PPAAm). The exact values for $\mathrm{MFI}_{\mathrm{B}}, \mathrm{MFI}_{\mathrm{A}}$ and slope can be found in Table 2. Stimulation with ATP after 180 s resulted in a significantly lower $\mathrm{Ca}^{2+}$ mobilization in cells on PSS and PDADMA compared with their Ti controls, whereas the $\mathrm{MFI}_{\mathrm{A}}$ of cells on Col I and PEI exceeded the Ti control significantly (Figure 5). Cells on Matrigel could not display a significantly different $\mathrm{Ca}^{2+}$ level upon stimulation than Ti. The $\mathrm{MFI}_{\mathrm{A}}$ in cells on RGD-functionalized surfaces was significantly elevated compared with Ti, but below PPAAm. The highest $\mathrm{Ca}^{2+}$ mobilization after ATP stimulation was found in cells on APTES. Cells cultured on PDADMA surfaces exhibited the lowest mobilization rate, while cells on PPI-G4 surfaces could not mobilize $\mathrm{Ca}^{2+}$ ions at all.

These results could be correlated with the $\zeta$-potential of the substrates, as shown in Figure 6. Here, the sections $5 \mathrm{~A}-\mathrm{C}$ are classified into negative, moderately and highly positive according to $\zeta$-potential values, starting with the most negative and ending with the most positive value. With this alignment the diminished $\mathrm{Ca}^{2+}$ mobilization in cells on surfaces with negative (Figure 6A) and highly positive $\zeta$-potential (Figure 6C) compared with surfaces with moderately positive $\zeta$-potential (Figure 6B) could be clearly demonstrated. Cells on surfaces with negative $\zeta$-potentials of -88.8 to $-43.3 \mathrm{mV}$ displayed significantly lower $\mathrm{Ca}^{2+}$ levels after ATP stimulation than PPAAm, the positively charged control (red line in highlighted area $=\mathrm{MFI}_{\mathrm{A}}$ of PPAAm) (Figure 6A). Exclusively, Col I-functionalized surfaces with an almost neutral $\zeta$-potential of $-2.8 \mathrm{mV}$ lacked significance to PPAAm. The absolute slope from basal $\mathrm{Ca}^{2+}$ level to the level after ATP stimulation reached a maximum of $594.9 \mathrm{MFI}_{\mathrm{C}}$ on negatively charged surfaces (Table 2 ).

Materials revealing a moderately positive $\zeta$-potential of $\sim 1$ to $10 \mathrm{mV}$ consistently exhibited significantly higher $\mathrm{Ca}^{2+}$ levels after stimulation than $\mathrm{Ti}$, the negatively charged control (black line in highlighted area $=\mathrm{MFI}_{\mathrm{A}}$ of Ti, Figure $\left.6 \mathrm{~B}\right)$. Here, the $\mathrm{Ca}^{2+}$ mobilization ranged between 800.7 and 1392.4 $\mathrm{MFI}_{\mathrm{C}}$ (Table 2).

On substrates presenting highly positive $\zeta$-potentials $(\sim+50 \mathrm{mV}), \mathrm{MG}-63$ s indicated an impaired $\mathrm{Ca}^{2+}$ mobilization with $\mathrm{MFI}_{\mathrm{A}}$ values significantly lower than PPAAm and $\mathrm{Ti}$ (Figure 6C). The maximum $\mathrm{Ca}^{2+}$ level increase was 79.1 $\mathrm{MFI}_{\mathrm{C}}$ (Table 2).

Furthermore, a correlation of $\mathrm{Ca}^{2+}$ mobilization data with the measured surface properties for wettability (WCA and SFE) could not be identified (Table 2). There were both less and more hydrophilic surfaces in the range of cells showing a stronger ability to mobilize intracellular $\mathrm{Ca}^{2+}$ (e.g., $\sim 90^{\circ}$ for APTES and $\sim 30^{\circ}$ for PEI) as well as a lower ability for $\mathrm{Ca}^{2+}$ mobilization (e.g., $\sim 90^{\circ}$ for $\mathrm{Ti}$ and $\sim 40^{\circ}$ for PDADMA). However, osteoblasts behave differently with respect to their $\mathrm{Ca}^{2+}$ dynamics. A similar statement can be formulated regarding the SFE values. Here, the highest SFE values (Col I $<$ PDADMA $<$ PPI-G4 $<$ PEI with 58.6, $62.0,62.4$, and $74.3 \mathrm{mN} / \mathrm{m}$, respectively) did not automatically lead to the best $\mathrm{Ca}^{2+}$ mobilization results, especially noticeable for PPI-G4 and PDADMA, which displayed the lowest slope.

\section{DISCUSSION}

Cells in living bone tissue are surrounded by an electrically charged, organic/inorganic solid that is permeated by a flow of ionic solution through an intricate channel system 


\section{Amino polymers}

APTES

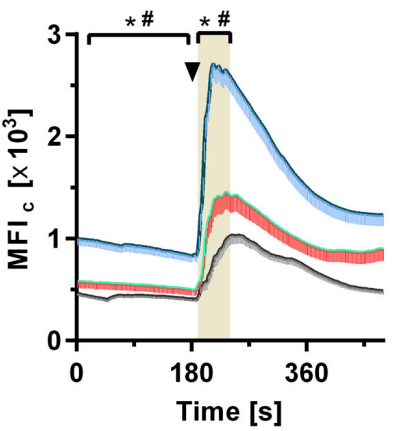

PEI

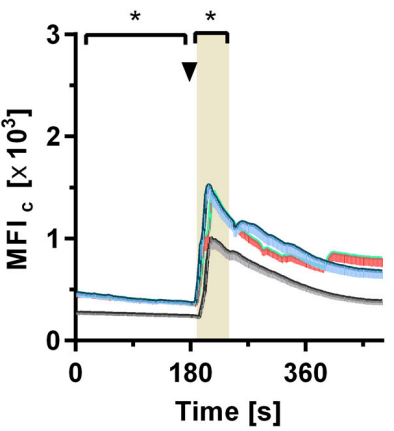

PPI-G4

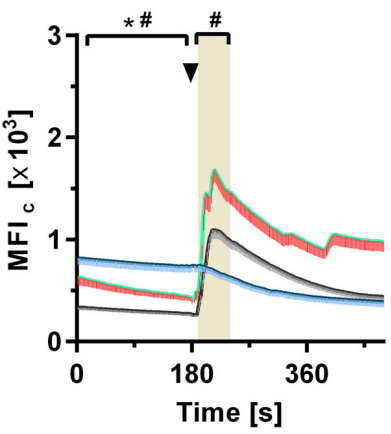

\section{ECM \& peptides}

Col I

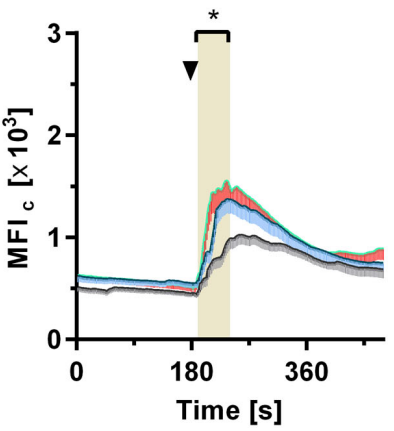

Matrigel

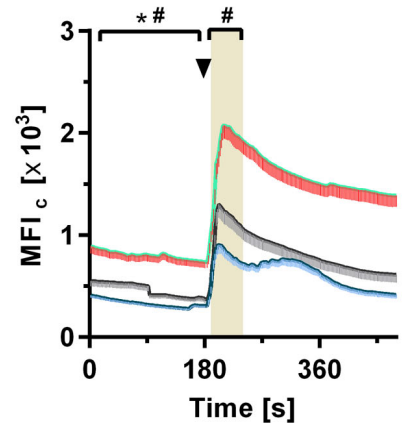

RGD

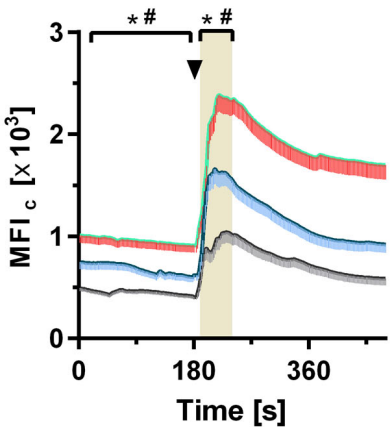

\section{PEM}

PSS

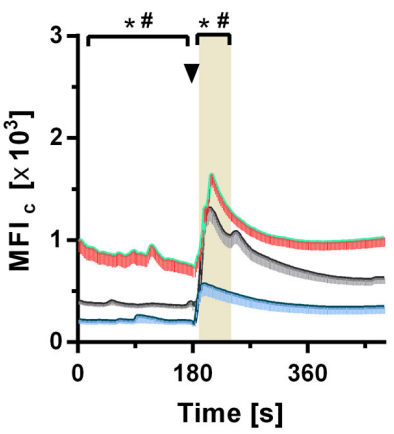

PDADMA

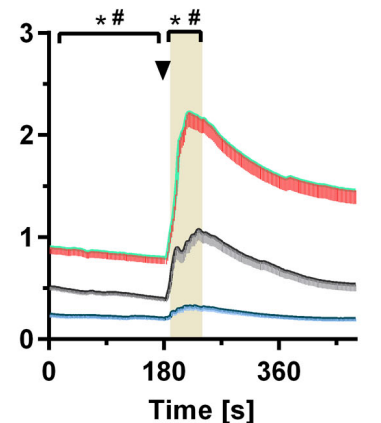

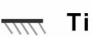

ताII PPAAm

गIII Modification $\mathrm{x}$

FIGURE 5 | Dynamic $\mathrm{Ca}^{2+}$ mobilization in vital fluo-3 loaded MG-63s growing on amino polymers, extracellular matrix (ECM)/peptide motifs and polyelectrolyte multilayers (PEM) in the time frame 0-480 s. The positive control PPAAm (also an amino polymer) and the negative control Ti are embedded for the respective experiment. Shown are time courses of the mean fluorescence intensity of cells $\left(\mathrm{MFI}_{\mathrm{C}}\right)$ over $8 \mathrm{~min}$ : First, the basal $\mathrm{Ca}^{2+}$ signal is recorded for $180 \mathrm{~s}$. At $180 \mathrm{~s}$ the cells are stimulated with ATP (arrowheads) and the $\mathrm{Ca}^{2+}$ signal is detected (LSM780, Carl Zeiss; ZEN-software). For statistical analyses of the basal MFI, values of the time points $0-170 \mathrm{~s}$ are used. For analyses of the MFI after ATP stimulation, values of the time points $190-240 \mathrm{~s}$ are used (highlighted in grey). $\mathrm{MFI}_{\mathrm{C}}$ values are normalized to the mean cell area after 24 h. (Statistics: Kruskal-Wallis and Dunn's multiple comparison test, $p<0.05$; mean \pm sem; $n \geq 3$ independent approaches, per time point $\geq 30$ cells; * indicates significance of modification $x$ to Ti and ${ }^{\#}$ significance to PPAAm).

(Chakkalakal, 1989). Consequently, it is not surprising that bone cell physiology is also affected by electrical cues when cultivating cells on artificial material surfaces. Cell-material interactions are highly complex and require more systematic investigations regarding surface charge. It is certain that electrostatic forces are crucial for cellular attachment via focal adhesion to material 


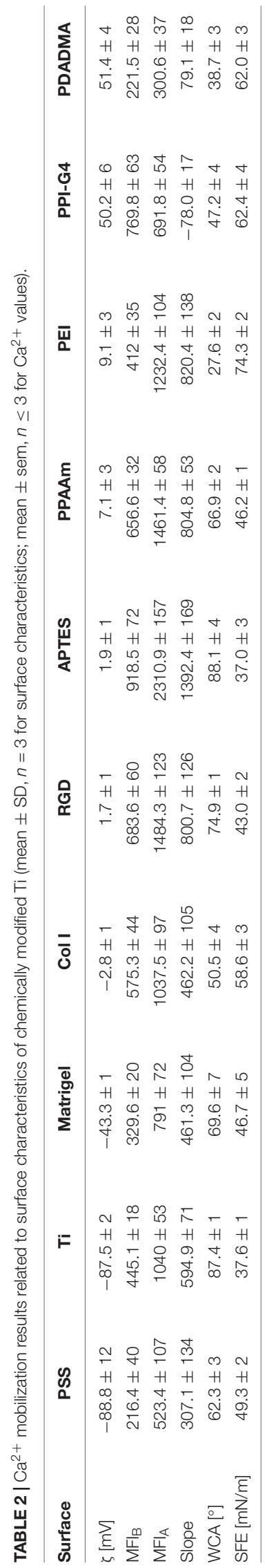

surfaces (Metwally and Stachewicz, 2019) influencing the further fate of cells. Earlier studies have mostly dealt with a limited number of surface charges [e.g., only negative surfaces (Altankov et al., 2003), one positive compared with several negative surfaces (Chang et al., 2014), or only one negative, neutral and positive surface charge (Iwai et al., 2013)] disallowing detailed statements. It has been reported that materials with positive surface potentials have a beneficial effect on cell viability as well as on adhesion and spreading. But most studies lacked a clear determination of the surface potential (Lee et al., 1994; Bacakova et al., 1996; Webb et al., 1998; Lesný et al., 2006). Hence, the underlying mechanism controlling cell activities using the materials' surface charge is still not fully understood in bone tissue engineering.

In the present study, the behavior of osteoblastic MG-63s via intracellular $\mathrm{Ca}^{2+}$ mobilization was systematically investigated on different Ti modifications and correlated with the materials' $\zeta$-potential as a parameter for the electric surface property. We used unmodified $\mathrm{Ti}(-87.5 \mathrm{mV})$ and PPAAm coated Ti $(+7.1 \mathrm{mV})$ as controls with negative and positive $\zeta$-potential, respectively, as published before (Mörke et al., 2017; Nebe et al., 2019), knowing that the PPAAm surface modification enhances cell physiology concerning adhesion, spreading, motility (Rebl et al., 2010), actin filament network (Rebl et al., 2016), viability and $\mathrm{Ca}^{2+}$ mobilization (Moerke et al., 2018; Staehlke et al., 2018), as well as the implant osseointegration (Hoene et al., 2010). Cells bind to this positively charged plasma polymer layer via electrostatic forces, as it is known that osteoblasts (Finke et al., 2007), epithelial cells and chondrocytes (Cohen et al., 2004) express i.a. the negatively charged hyaluronan as a spherical shell around the cells (Zimmerman et al., 2002). However, the question arose whether positive $\zeta$-potentials generally lead to a beneficial cellular outcome.

\section{Physico-Chemical Characterization of Ti Surface Coatings}

Therefore, we successfully prepared nine chemical modifications of Ti substrates with (i) amino polymers, (ii) ECM/peptide motifs, and (iii) PEM, resulting in a broad range of $\zeta$-potentials. The materials' characteristic $\zeta$-potential, WCA, SFE, layer thickness (Table 1) and chemical composition (Supplementary Table S2) were evaluated.

The layer thickness was in the nanometer range (max. $165 \mathrm{~nm}$ ). The APTES-modified surface layer was similar in thickness to the PEI and PPI-G4 layers. These layers are SAM arrangements, whereby the smaller thickness of the APTES layer correlates with the shorter molecular length of the APTES molecule compared with both the PEI and PPIG4 molecule lengths. The molecular length of the RGDconjugated APTES molecule is slightly longer than the APTES molecule itself. However, it is unlikely that an RGD molecule is coupled to every amino group on APTES. It therefore seems possible that individual RGD molecules are not necessarily aligned completely orthogonal to the surface as it is the case in a perfect SAM arrangement. In addition, interactions like hydrogen bonding between amino groups on APTES and residual amino acids of the RGD may possibly lead to a "bending" of the RGD molecules and consequently to a 


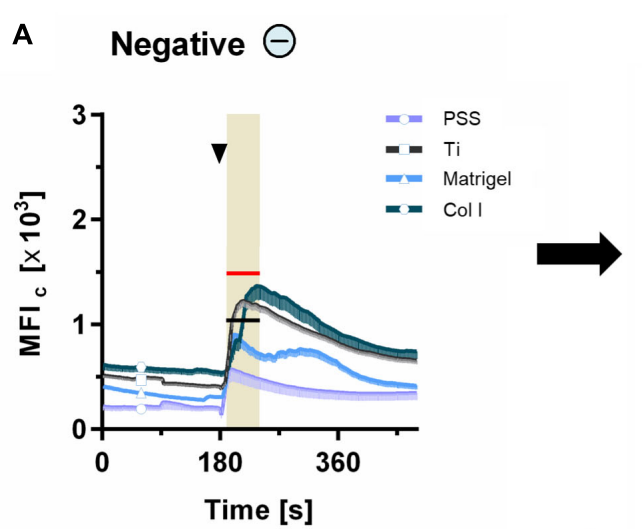

\section{$\mathrm{Ca}^{2+}$ mobilization}

$\hat{\Lambda}$

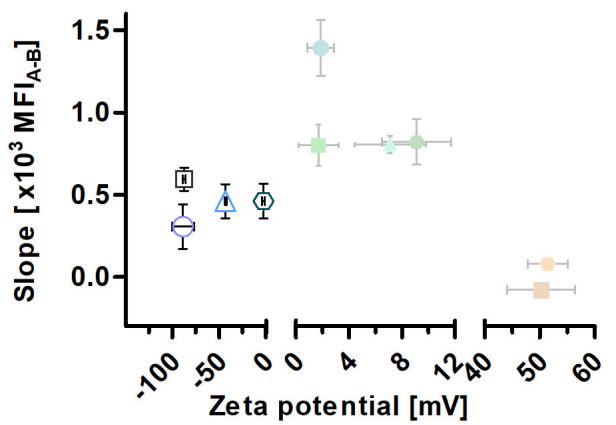

B $\quad$ Moderately positive $\oplus$

$\mathrm{Ca}^{2+}$ mobilization
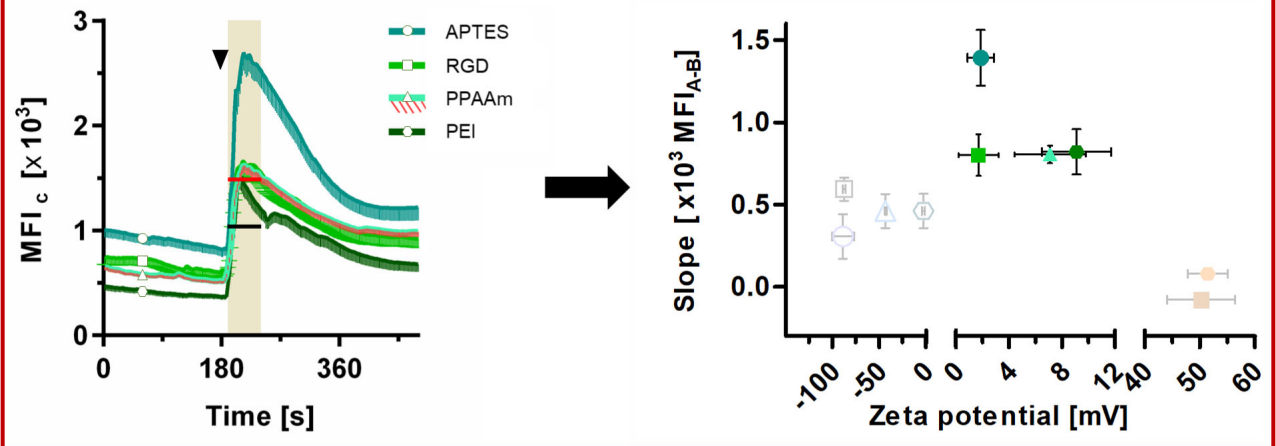

C Highly positive $\oplus \oplus$

v

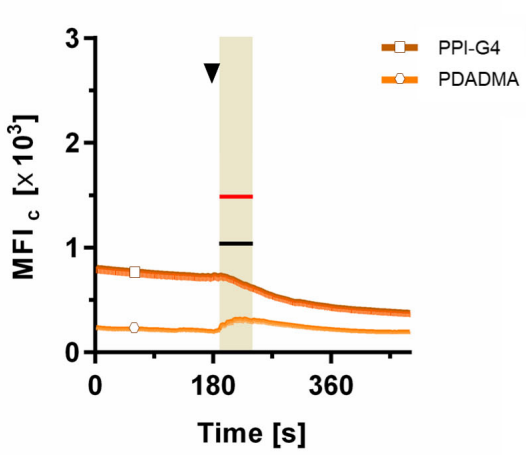

$\mathrm{Ca}^{2+}$ mobilization

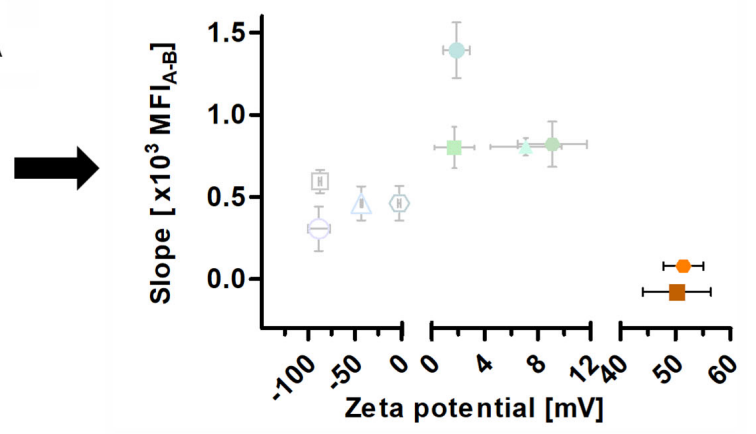

FIGURE 6 | $\mathrm{Ca}^{2+}$ mobilization results related to $\zeta$-potential. Presented are (i) the mean fluorescence intensity of cells (MFl $\mathrm{C}$ ) after $24 \mathrm{~h}$ on surfaces with (A) negative,

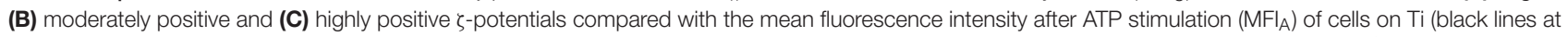
time points 170-240 s in highlighted area) and PPAAm (red lines at time points 170-240 s in highlighted area), and (ii) the correlation of the Ca ${ }^{2+}$ mobilization (slope) with the materials' $\zeta$-potentials. Note that the slope of the $\mathrm{Ca}^{2+}$ mobilization curve is strongly dependent on $\zeta$-potential values. Here, the surfaces with moderately positive $\zeta$-potentials indicate a beneficial impact. $\left(\mathrm{Ca}^{2+}\right.$ signaling: mean $\pm \mathrm{sem}, n \geq 3$ independent approaches, per time point $\geq 30$ cells for modifications and 190 cells for Ti and PPAAm controls, arrowheads at $180 \mathrm{~s}$ indicate ATP stimulation). PSS, poly(styrene sulfonate); Ti, titanium; Col I, collagen-type I; APTES,

(3-aminopropyl)triethoxysilan; RGD, peptide sequence Arg-Gly-Asp; PPAAm, plasma polymerized allylamine; PEI, poly(ethylene imine); PPI-G4, poly(propylene imine) dendrimer generation 4; PDADMA, poly(diallyldimethylammonium chloride).

reduction of the overall layer thickness. Regarding PPAAm coatings, it must be emphasized that PPAAm is a very complex, highly cross-linked structure, which was presented here only in a very simplified and model-like schematic manner (see Figure 1). The thickness of PPAAm, as well as Col I, Matrigel, and the polyelectrolyte multilayer coatings is mainly 
determined by the individual material properties and the process parameters.

The wettability analysis demonstrated a change to more hydrophilic surfaces. There is evidence that mammalian cells favor modestly hydrophilic surfaces displaying water contact angles between $40^{\circ}$ and $65^{\circ}$ (Rebl et al., 2012; Ahn et al., 2014; Gentleman and Gentleman, 2014). However, Gentleman and Gentleman (2014) reviewed that studies often lack a clear trend of cell behavior with wettability. They rather assumed SFE to be the more relevant feature for cellular behavior. This could not, however, be confirmed here. We could neither find a connection between WCA and SFE to the surface charge which is consistent with Olsson et al. (1995), nor a correlation with the cell behavior.

The $\zeta$-potential could rather be the pivotal parameter for controlling cell physiology in osteoblasts, as our results indicate. In whole bone tissue negative $\zeta$-potentials could be determined (Skalak and Shu, 1986; Otter et al., 1988; Chakkalakal, 1989). In this study, $\zeta$-potentials of the investigated surface modifications were identified in the range of -90 to $-3 \mathrm{mV}$ (PSS < Ti < Matrigel < Col I), +1 to $+10 \mathrm{mV}$ (RGD < APTES < PPAAm < PEI) and $\sim+50 \mathrm{mV}$ (PPIG4 < PDADMA). For the first time, we were able to classify the $\zeta$-potential into three categories with regard to an improved cell response on the respective surfaces and introduce the following terms: negative $<$ moderately positive $>$ highly positive.

\section{$\zeta$-Potential - A Parameter for Surface Charge - Can Strongly Influence Cellular Behavior}

It is known that physiology features of MG-63s such as actin cytoskeleton organization (Staehlke et al., 2015), viability (Staehlke et al., 2018) or proliferation (Labelle et al., 2007) are reflected by intracellular $\mathrm{Ca}^{2+}$ dynamics. However, to our knowledge there is no literature on intracellular $\mathrm{Ca}^{2+}$ dynamics in the context of the $\zeta$-potential of biomaterials other than our previously published study comparing surfaces with negative $\zeta$-potential with positive charges of plasma polymer nanolayers (PPAAm). The question remained, if positive charges in general promote the cellular outcome.

In order to gain deeper insights into the effect of surface charges on $\mathrm{Ca}^{2+}$ dynamics, we analyzed the intracellular $\mathrm{Ca}^{2+}$ signals before $\left(\mathrm{MFI}_{\mathrm{B}}\right)$ and after ATP stimulation $\left(\mathrm{MFI}_{\mathrm{A}}\right)$ on surface modifications with various charges using confocal laser scanning microscopy (Figure $\mathbf{5}$ and Supplementary Figure S5). Additionally, cell morphology (Figure 2), cell viability (Figure 3 and Supplementary Figure S1) and cell proliferation (Supplementary Figure S2) were investigated on selected surfaces. In the following, our results are discussed regarding negative, moderately and highly positive $\zeta$-potentials.

\section{Negative $\zeta$-Potential $(-90$ to $-3 \mathrm{mV})$}

On our surfaces with negative $\zeta$-potential we found evidence of reduced $\mathrm{Ca}^{2+}$ mobilization after $24 \mathrm{~h}$ compared with surfaces with moderately positive $\zeta$-potential. On PSS terminated PEM surfaces, MG-63s showed one of the lowest $\mathrm{Ca}^{2+}$ slopes after $24 \mathrm{~h}$. Other studies documented that hMSC cell numbers after 2, 5, and 7 days were consistently lower on PSS terminated PEM films than on control surfaces (Liao et al., 2010). However, PSS ending films exhibited good biocompatibility, as shown for SaOS-2 cells (cytokine IL-8 production) (Tryoen-Tóth et al., 2002), at least for films consisting of not more than six polyelectrolyte layers (Arias et al., 2016).

\section{Moderately Positive $\zeta$-Potential ( +1 to $+10 \mathrm{mV}$ )}

Surfaces in the moderately positively charged range were found to promote the cell physiology via $\mathrm{Ca}^{2+}$ mobilization. Cells can access their intracellular $\mathrm{Ca}^{2+}$ stores more effectively after an external stimulus (here: ATP) than cells on negatively charged substrates, suggesting higher cell activities.

Ravenscroft-Chang et al. (2010) loaded primary cardiac myocytes growing on (3-trimethoxysilylpropyl) diethylenetriamine (DETA) silane modified and fluorinated glass substrates with fura-2 AM and induced a $\mathrm{Ca}^{2+}$ signal by electrical stimulation (1 HZ, $6 \mathrm{~V}, 5 \mathrm{~ms} /$ pulse). Cells exhibited a significantly higher $\mathrm{Ca}^{2+}$ level, as shown in higher amplitude and duration. However, the authors did not determine the $\zeta$-potential of their surfaces. But a slightly positive $\zeta$-potential at $\mathrm{pH} 7.4$ of such DETA amino silane treated glass surfaces was measured earlier by Metwalli et al. (2006) supporting the idea of higher cellular activity on the basis of moderately positive charges.

For PEI functionalized surfaces it is known that cytotoxicity can exist depending on the molecular weight and concentration (Brunot et al., 2007). However, in studies with surfaces derived from low molecular weight PEI, as used here $(25 \mathrm{kDa})$, no cytotoxic effects were reported for fibroblasts up to 7 days (Hernandez-Montelongo et al., 2017). PEI modification could further improve proliferation and function of MG-63s (Liu et al., 2009), as indicated here by an increased $\mathrm{Ca}^{2+}$ slope.

RGD peptide motifs covalently bonded to Ti surfaces promote osteoblast attachment and survival (Secchi et al., 2007). ElGhannam et al. (2004) showed that APTES-RGD coatings provided the optimal surface for cell adhesion, spreading, and cytoskeletal organization for MC3T3-El cells, better than RGD and APTES alone. It must be taken into consideration that surfaces modified with RGD (as well as Col I and Col IV and laminin containing Matrigel) can trigger $\mathrm{Ca}^{2+}$ mobilization through integrin mediated "outside-in" signal transduction during cell adhesion (Sjaastad and Nelson, 1997; Boraschi-Diaz et al., 2017). After 24 h cultivation, however, integrin signaling may no longer be that influential in this case, as no additional stimulus such as mechanical stress (Pommerenke et al., 2002) was applied. Otherwise an increased $\mathrm{Ca}^{2+}$ mobilization on these ECM coated surfaces would be expected. Here, we found that APTES alone was capable of mobilizing $\mathrm{Ca}^{2+}$ in $\mathrm{MG}$ 63s even more than PPAAm - surfaces that do not present integrin ligands.

Lee et al. (2018) presented ATPES-treated PDMS concave microwell surfaces to cortical neurons which revealed optimal surface conditions additionally supporting a spheroid formation. The authors also stimulated the cells with $\mathrm{KCl}$ for spontaneous calcium transients (fluo-4 AM), observing typical temporal $\mathrm{Ca}^{2+}$ responses in all chemically modified microwells based on APTES (APTES, APTES-Laminin, APTES-poly-L-lysine, APTES-carbon nanotubes). 


\section{Highly Positive $\zeta$-Potentials $(\sim+50 \mathrm{mV})$}

On PPI-G4 and PDADMA surfaces with highly positive $\zeta$-potentials we discovered a restricted cell viability, reflected in an impaired $\mathrm{Ca}^{2+}$ mobilization and a disturbed cell morphology and proliferation after $24 \mathrm{~h}$, indicating that cells cannot tolerate such $\zeta$-potentials.

Koch et al. (2018) produced the 11-amino acid self-assembling peptides P11-8 and P11-28/29 hydrogels exhibiting $\zeta$-potentials of $\sim+20 \mathrm{mV}$ and $\sim+60 \mathrm{mV}$ at $\mathrm{pH} 7.0$, respectively. HPDLF and HCO cells on highly positive P11-28/29 surfaces showed reduced cell area after $24 \mathrm{~h}$, while cells on P11-8 displayed also enhanced osteogenic differentiation (ALP activity) compared with hydrogels containing negatively charged glutamic acids. Similarly, Kidambi et al. (2004) reported that primary hepatocytes were unable to remain attached to PEM films with PDADMA as the outermost layer. Inactive cells completely lifted off the surface by day 7 where liver-specific functions approached zero. In our previous study (Gruening et al., 2020) we found an impeded cell spreading dynamic on PDADMA surfaces after an initial tendency to spread better than Ti. The longer the influence of strongly positive charges on the cells, the more the cells were hampered.

Guo et al. (2018) pointed out that on positively charged noncross-linked PEI films ( $\zeta$-potential: +50 and $+62 \mathrm{mV}$ ) more fibroblasts could adhere within the first $24 \mathrm{~h}$ compared with negatively charged polymer films. But, on the second day, cells on the negatively charged surfaces proliferated well, in contrast to those on samples with high $\zeta$-potentials. The authors argued that this was due to the reported cytotoxicity of PEI. But by cross-linking these PEI films, the high $\zeta$-potential was reduced to $\sim+20 \mathrm{mV}$ and cells proliferated on all surfaces.

During the cell cycle, checkpoints in G1 and G2 (gap) phases prevent cells from entering into the next phase in case of cell injury e.g., due to accumulation of reactive oxygen species (ROS) (Muller et al., 2007) or inadequate environmental conditions such as bacterial infection (Kato et al., 2008), hypoxia (Zou et al., 2015) or withdrawal of nutrition (Blagosklonny, 2011). Cells which do not pass the safety controls proceed with the nonproliferative G0/G1 phase in quiescence (cell cycle arrest) or even permanent senescence (Blagosklonny, 2011; Terzi et al., 2016). We found an increasing cell amount in the G1 phase on highly positive surfaces, leading to a decline of cellular proliferation. In further experiments it is to be examined whether the high surface charges lead to an elevated ROS production as stress response and thus to a cell cycle arrest, allowing cells to cope with their environment.

However, the high surface charge leads to an intense interaction with the negatively charged cell surface (Rebl et al., 2016), which is further considered to cause damaged lipid bilayers due to new vesicular structures around the cationic molecules which create holes in the cell membrane (Mecke et al., 2005). This could be supported by the live/dead staining, demonstrating an abolished membrane integrity in still vital cells on PPIG4 and PDADMA.

The adverse effects of highly positive surface charges deduced from the $\zeta$-potential might also be indirectly linked to protein adsorption, since it has been published that the protein adsorption is strongly affected by the $\zeta$-potential (Krajewski et al., 1998; Lehnfeld et al., 2020) influencing the protein population (Shelton et al., 1988) and orientation (Norde and Lyklema, 1991; Antonini et al., 2014). Therefore, a further correlation between protein adsorption and $\zeta$-potential of different surface modifications with well-defined effects on the cell behavior is of great interest.

\section{CONCLUSION}

This is the largest systematic study so far documenting the importance of the materials' surface charge deduced from $\zeta$-potential for the intracellular $\mathrm{Ca}^{2+}$ dynamics and viability of human osteoblasts. Positive charges offer unique cues that induce an intensive cell response. But interestingly, we identified that cells favor only a certain range of moderately positive surface charges and not a positively charged surface in general. The $\zeta$-potential appears to be a key property of biomaterial surfaces dominating the relevance of wettability (WCA, SFE), and should be considered in biomaterial coating design in tissue engineering and dental and orthopedic implantology.

\section{DATA AVAILABILITY STATEMENT}

The datasets presented in this study can be found in online repositories. The names of the repository/repositories and accession number(s) can be found below: Mendeley data doi: 10.17632/h8rs6v4dgt.1.

\section{AUTHOR CONTRIBUTIONS}

MG: conceptualization, investigation, validation, visualization, and original draft preparation. SN: PEM preparation. PN: layer thickness measurement and review and editing. KF: XPS measurement and PPAAm preparation. MD: APTES and RGD preparation. JL: PEI and PPI-G4 preparation and review and editing. MS: visualization and review and editing. $\mathrm{CH}$ and RM: review and editing and funding acquisition. SS: ATP receptor immunofluorescence and review and editing. JBN: conceptualization, review and editing, project administration, and funding acquisition. All authors contributed to the article and approved the submitted version.

\section{FUNDING}

This project was supported by the Deutsche Forschungsgemeinschaft (DFG, German Research Foundation) Collaborative Research Center (CRC) 1270/1 ELAINE 299150580. JL was supported by the Fonds der Chemischen Industrie (FCI) with the Chemiefonds Fellowship. 


\section{ACKNOWLEDGMENTS}

We thank Dr. Marcus Frank and Dr. Armin Springer (Electron Microscopy Center, University Medical Center Rostock) concerning SEM sample preparation and the cooperation with Dipl.-Ing. Norbert Zichner (Center for Microtechnologies, TU Chemnitz) concerning the production of the titanium-coated materials. We acknowledge Petra Seidel (Cell Biology, University Medical Center Rostock) for her technical assistance concerning MTS assay, Dr. Matthias Kronseder (Physics, University of Regensburg)

\section{REFERENCES}

Abalymov, A., Van der Meeren, L., Skirtach, A. G., and Parakhonskiy, B. V. (2020). Identification and analysis of key parameters for the ossification on particle functionalized composites hydrogel materials. ACS Appl. Mater. Interf. 2020:acsami.0c06641. doi: 10.1021/acsami.0c06641

Ahn, H., Lee, I., Lee, H., and Kim, M. (2014). Cellular behavior of human adiposederived stem cells on wettable gradient polyethylene surfaces. Int. J. Mol. Sci. 15, 2075-2086. doi: 10.3390/ijms15022075

Akter, F., and Ibanez, J. (2016). Bone and cartilage tissue engineering. Tissue Eng. Made Easy 2016, 77-97. doi: 10.1016/B978-0-12-805361-4. 00008-4

Altankov, G., Richau, K., and Groth, T. (2003). The role of surface zeta potential and substratum chemistry for regulation of dermal fibroblasts interaction. Materwiss. Werksttech. 34, 1120-1128. doi: 10.1002/mawe.200300699

Anselme, K., Ponche, A., and Bigerelle, M. (2010). Relative influence of surface topography and surface chemistry on cell response to bone implant materials. Part 2: biological aspects. Proc. Inst. Mech. Eng. H 224, 1487-1507. doi: 10.1243/ 09544119JEIM901

Antonini, V., Torrengo, S., Marocchi, L., Minati, L., Serra, M. D., Bao, G., et al. (2014). Combinatorial plasma polymerization approach to produce thin films for testing cell proliferation. Coll. Surf. B Biointerf. 113, 320-329. doi: 10.1016/ J.COLSURFB.2013.09.020

Arias, C. J., Surmaitis, R. L., and Schlenoff, J. B. (2016). Cell adhesion and proliferation on the "living" surface of a polyelectrolyte multilayer. Langmuir 32, 5412-5421. doi: 10.1021/acs.langmuir.6b00784

Bacakova, L., Filova, E., Parizek, M., Ruml, T., and Svorcik, V. (2011). Modulation of cell adhesion, proliferation and differentiation on materials designed for body implants. Biotechnol. Adv. 29, 739-767. doi: 10.1016/J.BIOTECHADV.2011.06. 004

Bacakova, L., Svorcik, V., Rybka, V., Micek, I., Hnatowicz, V., Lisa, V., et al. (1996). Adhesion and proliferation of cultured human aortic smooth muscle cells on polystyrene implanted with $\mathrm{N}+, \mathrm{F}+$ and Ar+ ions: correlation with polymer surface polarity and carbonization. Biomaterials 17, 1121-1126. doi: 10.1016/0142-9612(96)85914-X

Blagosklonny, M. V. (2011). Cell cycle arrest is not senescence. Aging 3, 94-101. doi: 10.18632/aging.100281

Boraschi-Diaz, I., Wang, J., Mort, J. S., and Komarova, S. V. (2017). Collagen Type I as a Ligand for receptor-mediated signaling. Front. Phys. 5:12. doi: 10.3389/fphy.2017.00012

Brunot, C., Ponsonnet, L., Lagneau, C., Farge, P., Picart, C., and Grosgogeat, B. (2007). Cytotoxicity of polyethyleneimine (PEI), precursor base layer of polyelectrolyte multilayer films. Biomaterials 28, 632-640. doi: 10.1016/J. BIOMATERIALS.2006.09.026

Cao, C., Song, Y., Yao, Q., Yao, Y., Wang, T., Huang, B., et al. (2015). Preparation and preliminary in vitro evaluation of a bFGF-releasing heparin-conjugated poly( $\varepsilon$-caprolactone) membrane for guided bone regeneration. J. Biomater. Sci. Polym. Edn. 26, 600-616. doi: 10.1080/09205063.2015.1049044

Chakkalakal, D. A. (1989). Mechanoelectric transduction in bone. J. Mater. Res. 4, 1034-1046. doi: 10.1557/JMR.1989.1034

Chang, H.-Y., Huang, C.-C., Lin, K.-Y., Kao, W.-L., Liao, H.-Y., You, Y.-W., et al. (2014). Effect of surface potential on NIH3T3 cell adhesion and proliferation. J. Phys. Chem. C 118, 14464-14470. doi: 10.1021/jp504662c for XPS analyses of PEI and PPI-G4, and Dr. Frank Krueger (Communications Engineering, University of Rostock) for providing the digital laboratory book eLab-FTW within the CRC ELAINE.

\section{SUPPLEMENTARY MATERIAL}

The Supplementary Material for this article can be found online at: https://www.frontiersin.org/articles/10.3389/fbioe. 2020.01016/full\#supplementary-material

Chen, S., Guo, Y., Liu, R., Wu, S., Fang, J., Huang, B., et al. (2018). Tuning surface properties of bone biomaterials to manipulate osteoblastic cell adhesion and the signaling pathways for the enhancement of early osseointegration. Coll. Surf. B Biointerf. 164, 58-69. doi: 10.1016/J.COLSURFB.2018.01.022

Clover, J., and Gowen, M. (1994). Are MG-63 and HOS TE85 human osteosarcoma cell lines representative models of the osteoblastic phenotype? Bone 15, 585591. doi: 10.1016/8756-3282(94)90305-0

Cohen, M., Joester, D., Geiger, B., and Addadi, L. (2004). Spatial and temporal sequence of events in cell adhesion: from molecular recognition to focal adhesion assembly. Chembiochem 5, 1393-1399. doi: 10.1002/cbic.200400162

Czekanska, E. M., Stoddart, M. J., Ralphs, J. R., Richards, R. G., and Hayes, J. S. (2014). A phenotypic comparison of osteoblast cell lines versus human primary osteoblasts for biomaterials testing. J. Biomed. Mater. Res. Part A 102, 2636-2643. doi: 10.1002/jbm.a.34937

De Aza, P. N., Luklinska, Z. B., Santos, C., Guitian, F., and De Aza, S. (2003). Mechanism of bone-like formation on a bioactive implant in vivo. Biomaterials 24, 1437-1445. doi: 10.1016/S0142-9612(02)00530-6

Devgan, S., and Sidhu, S. S. (2019). Evolution of surface modification trends in bone related biomaterials: a review. Mater. Chem. Phys. 233, 68-78. doi: 10.1016/J. MATCHEMPHYS.2019.05.039

Dhowre, H. S., Rajput, S., Russell, N. A., and Zelzer, M. (2015). Responsive cell-material interfaces. Nanomedicine 10, 849-871. doi: 10.2217/nnm.14.222

Eichler, M., Katzur, V., Scheideler, L., Haupt, M., Geis-Gerstorfer, J., Schmalz G., et al. (2011). The impact of dendrimer-grafted modifications to model silicon surfaces on protein adsorption and bacterial adhesion. Biomaterials 32, 9168-9179. doi: 10.1016/J.BIOMATERIALS.2011.08.063

El-Ghannam, A. R., Ducheyne, P., Risbud, M., Adams, C. S., Shapiro, I. M., Castner, D., et al. (2004). Model surfaces engineered with nanoscale roughness and RGD tripeptides promote osteoblast activity. J. Biomed. Mater. Res. 68A, 615-627. doi: 10.1002/jbm.a.20051

Felgueiras, H. P., Antunes, J. C., Martins, M. C. L., and Barbosa, M. A. (2018). Fundamentals of protein and cell interactions in biomaterials. Pept. Proteins Biomater. Tissue Regen. Repair 88, 956-970. doi: 10.1016/B978-0-08-100803-4. 00001-2

Fernández-Yagüe, M., Antoñanzas, R. P., Roa, J. J., Biggs, M., Gil, F. J., and Pegueroles, M. (2019). Enhanced osteoconductivity on electrically charged titanium implants treated by physicochemical surface modifications methods. Nanomed. Nanotechnol. Biol. Med. 18, 1-10. doi: 10.1016/J.NANO.2019.02.005

Ferrari, M., Cirisano, F., and Morán, M. C. (2019). Mammalian cell behavior on hydrophobic substrates: influence of surface properties. Colloids Interf. 3:48. doi: 10.3390/colloids3020048

Ferraris, S., Cazzola, M., Peretti, V., Stella, B., and Spriano, S. (2018). Zeta potential measurements on solid surfaces for in vitro biomaterials testing: surface charge, reactivity upon contact with fluids and protein absorption. Front. Bioeng. Biotechnol. 6:60. doi: 10.3389/fbioe.2018.00060

Finke, B., Luethen, F., Schroeder, K., Mueller, P. D., Bergemann, C., Frant, M., et al. (2007). The effect of positively charged plasma polymerization on initial osteoblastic focal adhesion on titanium surfaces. Biomaterials 28, 4521-4534. doi: 10.1016/J.BIOMATERIALS.2007.06.028

Finke, B., Rebl, H., Hempel, F., Schäfer, J., Liefeith, K., Weltmann, K.-D., et al. (2014). Aging of plasma-polymerized allylamine nanofilms and the maintenance of their cell adhesion capacity. Langmuir 30, 13914-13924. doi: 10.1021/la5019778 
Fritsche, A., Haenle, M., Zietz, C., Mittelmeier, W., Neumann, H.-G., Heidenau, F., et al. (2009). Mechanical characterization of anti-infectious, anti-allergic, and bioactive coatings on orthopedic implant surfaces. J. Mater. Sci. 44, 5544-5551. doi: 10.1007/s10853-009-3776-1

Gentleman, M. M., and Gentleman, E. (2014). The role of surface free energy in osteoblast-biomaterial interactions. Int. Mater. Rev. 59, 417-429. doi: 10.1179/ 1743280414Y.0000000038

Goldenberg, N. M., and Steinberg, B. E. (2010). Surface charge: a key determinant of protein localization and function. Cancer Res. 70, 1277-1280. doi: 10.1158/ 0008-5472.CAN-09-2905

Gruening, M., Neuber, S., Fricke, K., Helm, C. A., and Nebe, B. (2020). Cellmaterial interaction - spreading course correlates with surface charge. Am. J. Biomed. Sci. Res. 9, 4-6. doi: 10.34297/AJBSR.2020.09.001341

Guo, S., Kwek, M. Y., Toh, Z. Q., Pranantyo, D., Kang, E.-T., Loh, X. J., et al. (2018). Tailoring polyelectrolyte architecture to promote cell growth and inhibit bacterial adhesion. ACS Appl. Mater. Interf. 10, 7882-7891. doi: 10.1021/acsami. $8 \mathrm{~b} 00666$

Hanawa, T. (2019). Titanium-tissue interface reaction and its control with surface treatment. Front. Bioeng. Biotechnol. 7:170. doi: 10.3389/fbioe.2019.00170

Heo, W., Do Inoue, T., Park, W. S., Kim, M. L., Park, B. O., Wandless, T. J., et al. (2006). PI(3,4,5)P3 and PI(4,5)P2 lipids target proteins with polybasic clusters to the plasma membrane. Science 314, 1458-1461. doi: 10.1126/SCIENCE. 1134389

Hernandez-Montelongo, J., Lucchesi, E. G., Nascimento, V. F., França, C. G., Gonzalez, I., Macedo, W. A. A., et al. (2017). Antibacterial and non-cytotoxic ultra-thin polyethylenimine film. Mater. Sci. Eng. C 71, 718-724. doi: 10.1016/ J.MSEC.2016.10.064

Hoene, A., Walschus, U., Patrzyk, M., Finke, B., Lucke, S., Nebe, B., et al. (2010). In vivo investigation of the inflammatory response against allylamine plasma polymer coated titanium implants in a rat model. Acta Biomater. 6, 676-683. doi: 10.1016/J.ACTBIO.2009.09.003

Iwai, R., Nemoto, Y., and Nakayama, Y. (2013). The effect of electrically charged polyion complex nanoparticle-coated surfaces on adipose-derived stromal progenitor cell behaviour. Biomaterials 34, 9096-9102. doi: 10.1016/J. BIOMATERIALS.2013.08.027

Kato, T., Tsuda, T., Inaba, H., Kawai, S., Okahashi, N., Shibata, Y., et al. (2008). Porphyromonas gingivalis gingipains cause $\mathrm{G}(1)$ arrest in osteoblastic/stromal cells. Oral Microbiol. Immunol. 23, 158-164. doi: 10.1111/j.1399-302X.2007. 00405.x

Katzur, V., Eichler, M., Deigele, E., Stage, C., Karageorgiev, P., Geis-Gerstorfer, J., et al. (2012). Surface-immobilized PAMAM-dendrimers modified with cationic or anionic terminal functions: physicochemical surface properties and conformational changes after application of liquid interface stress. J. Coll. Interf. Sci. 366, 179-190. doi: 10.1016/J.JCIS.2011.09.029

Kennedy, S. B., Washburn, N. R., Simon, C. G., and Amis, E. J. (2006) Combinatorial screen of the effect of surface energy on fibronectin-mediated osteoblast adhesion, spreading and proliferation. Biomaterials 27, 3817-3824. doi: 10.1016/J.BIOMATERIALS.2006.02.044

Kidambi, S., Ilsoon, L., and Chan, C. (2004). Controlling primary hepatocyte adhesion and spreading on protein-free polyelectrolyte multilayer films. J. Am Chem. Soc. 126, 16286-16287. doi: 10.1021/JA046188U

Koch, F., Wolff, A., Mathes, S., Pieles, U., Saxer, S., Kreikemeyer, B., et al. (2018). Amino acid composition of nanofibrillar self-assembling peptide hydrogels affects responses of periodontal tissue cells in vitro. Int. J. Nanomed. 13, 6717-6733. doi: 10.2147/IJN.S173702

Kokubo, T., and Yamaguchi, S. (2015). Growth of novel ceramic layers on metals via chemical and heat treatments for inducing various biological functions. Front Bioeng. Biotechnol. 3:176. doi: 10.3389/fbioe.2015.00176

Krajewski, A., Piancastelli, A., and Malavolti, R. (1998). Albumin adhesion on ceramics and correlation with their Z-potential. Biomaterials 19, 637-641. doi: 10.1016/S0142-9612(97)00153-1

Kumar, P. S., Sathesh, K., Grandhi, V. V., and Gupta, V. (2019). The effects of titanium implant surface topography on osseointegration: literature review. JMIR Biomed. Eng. 4:e13237. doi: 10.2196/13237

Labelle, D., Jumarie, C., and Moreau, R. (2007). Capacitative calcium entry and proliferation of human osteoblast-like MG-63 cells. Cell Prolif. 40, 866-884. doi: 10.1111/j.1365-2184.2007.00477.x
Lee, G., Lim, J., Park, J., Lee, W., Yoon, D. S., Kim, S. H., et al. (2018). Construction of neurospheroids via surface modified concave microwells. J. Ind. Eng. Chem. 62, 341-351. doi: 10.1016/J.JIEC.2018.01.014

Lee, J. H., Jung, H. W., Kang, I.-K., and Lee, H. B. (1994). Cell behaviour on polymer surfaces with different functional groups. Biomaterials 15, 705-711. doi: 10.1016/0142-9612(94)90169-4

Lehnfeld, J., Gruening, M., Kronseder, M., and Mueller, R. (2020). Comparison of protein-repellent behavior of linear versus dendrimer-structured surfaceimmobilized polymers. Langmuir 2020:acs.langmuir.0c00625. doi: 10.1021/acs. langmuir.0c00625

Lesný, P., Přádný, M., Jendelová, P., Michálek, J., Vacík, J., and Syková, E. (2006). Macroporous hydrogels based on 2-hydroxyethyl methacrylate. Part 4: growth of rat bone marrow stromal cells in three-dimensional hydrogels with positive and negative surface charges and in polyelectrolyte complexes. J. Mater. Sci. Mater. Med. 17, 829-833. doi: 10.1007/s10856-006-9842-1

Liao, T., Moussallem, M. D., Kim, J., Schlenoff, J. B., and Ma, T. (2010). Nisopropylacrylamide-based thermoresponsive polyelectrolyte multilayer films for human mesenchymal stem cell expansion. Biotechnol. Prog. 26, 1705-1713. doi: 10.1002/btpr.471

Liu, Q., Ding, J., Mante, F. K., Wunder, S. L., and Baran, G. R. (2002). The role of surface functional groups in calcium phosphate nucleation on titanium foil: a self-assembled monolayer technique. Biomaterials 23, 3103-3111. doi: 10.1016/ S0142-9612(02)00050-9

Liu, Z.-M., Lee, S.-Y., Sarun, S., Peschel, D., and Groth, T. (2009). Immobilization of poly (ethylene imine) on poly (l-lactide) promotes MG63 cell proliferation and function. J. Mater. Sci. Mater. Med. 20, 2317-2326. doi: 10.1007/s10856009-3806-1

Mecke, A., Majoros, I. J., Patri, A. K., Baker, J. R., Banaszak Holl, M. M., and Orr, B. G. (2005). Lipid bilayer disruption by polycationic polymers:? the roles of size and chemical functional group. Langmuir 21, 10348-10354. doi: 10.1021/ la0506291

Metwalli, E., Haines, D., Becker, O., Conzone, S., and Pantano, C. G. (2006). Surface characterizations of mono-, di-, and tri-aminosilane treated glass substrates. J. Coll. Interf. Sci. 298, 825-831. doi: 10.1016/J.JCIS.2006.03.045

Metwally, S., and Stachewicz, U. (2019). Surface potential and charges impact on cell responses on biomaterials interfaces for medical applications. Mater. Sci. Eng. C 104:109883. doi: 10.1016/J.MSEC.2019.109883

Moerke, C., Staehlke, S., Rebl, H., Finke, B., and Nebe, J. B. (2018). Restricted cell functions on micropillars are alleviated by surfacenanocoating with amino groups. J. Cell Sci. 131:jcs207001. doi: 10.1242/jcs.207001

Mohamad, H. S., Neuber, S., and Helm, C. A. (2019). Surface forces of asymmetrically grown polyelectrolyte multilayers: searching for the charges. Langmuir 35, 15491-15499. doi: 10.1021/acs.langmuir.9b01787

Mörke, C., Rebl, H., Finke, B., Dubs, M., Nestler, P., Airoudj, A., et al. (2017). Abrogated cell contact guidance on amino-functionalized microgrooves. ACS Appl. Mater. Interf. 9, 10461-10471. doi: 10.1021/acsami.6b16430

Muderrisoglu, C., Saveleva, M., Abalymov, A., Van der Meeren, L., Ivanova, A., Atkin, V., et al. (2018). Nanostructured biointerfaces based on bioceramic calcium carbonate/hydrogel coatings on titanium with an active enzyme for stimulating osteoblasts growth. Adv. Mater. Interf. 5:1800452. doi: 10.1002/ admi.201800452

Muller, F. L., Lustgarten, M. S., Jang, Y., Richardson, A., and Van Remmen, H. (2007). Trends in oxidative aging theories. Free Radic. Biol. Med. 43, 477-503. doi: 10.1016/J.FREERADBIOMED.2007.03.034

Müller, R., Abke, J., Schnell, E., Scharnweber, D., Kujat, R., Englert, C., et al. (2006). Influence of surface pretreatment of titanium- and cobalt-based biomaterials on covalent immobilization of fibrillar collagen. Biomaterials 27, 4059-4068. doi: 10.1016/J.BIOMATERIALS.2006.03.019

Nebe, B., Finke, B., Lüthen, F., Bergemann, C., Schröder, K., Rychly, J., et al. (2007). Improved initial osteoblast functions on amino-functionalized titanium surfaces. Biomol. Eng. 24, 447-454. doi: 10.1016/J.BIOENG.2007.07.004

Nebe, J. B., Rebl, H., Schlosser, M., Staehlke, S., Gruening, M., Weltmann, K.D., et al. (2019). Plasma polymerized allylamine-the unique cell-attractive nanolayer for dental implant materials. Polymers 11:1004. doi: 10.3390/ polym 11061004

Nestler, P., Block, S., and Helm, C. A. (2012). Temperature-induced transition from odd-even to even-odd effect in polyelectrolyte multilayers due to 
interpolyelectrolyte interactions. J. Phys. Chem. B 116, 1234-1243. doi: 10.1021/ jp208837m

Nikkhah, M., Edalat, F., Manoucheri, S., and Khademhosseini, A. (2012). Engineering microscale topographies to control the cell-substrate interface. Biomaterials 33, 5230-5246. doi: 10.1016/J.BIOMATERIALS.2012.03.079

Norde, W., and Lyklema, J. (1991). Why proteins prefer interfaces. J. Biomater. Sci. Polym. Edn. 2, 183-202. doi: 10.1080/09205063.1991.9756659

Olsson, J., Carlén, A., Burns, N. L., and Holmberg, K. (1995). Modified pellicle formation and reduced in vitro bacterial adherence after surface treatment with different siloxane polymers. Coll. Surf. B Biointerf. 5, 161-169. doi: 10.1016/ 0927-7765(95)01212-2

Otter, M., Goheen, S., and Williams, W. S. (1988). Streaming potentials in chemically modified bone. J. Orthop. Res. 6, 346-359. doi: 10.1002/jor. 1100060306

Padial-Molina, M., Galindo-Moreno, P., Fernández-Barbero, J. E., O’Valle, F., Jódar-Reyes, A. B., Ortega-Vinuesa, J. L., et al. (2011). Role of wettability and nanoroughness on interactions between osteoblast and modified silicon surfaces. Acta Biomater. 7, 771-778. doi: 10.1016/J.ACTBIO.2010.08.024

Pommerenke, H., Schmidt, C., Dürr, F., Nebe, B., Lüthen, F., Muller, P., et al. (2002). The mode of mechanical integrin stressing controls intracellular signaling in osteoblasts. J. Bone Miner. Res. 17, 603-611. doi: 10.1359/jbmr. 2002.17.4.603

Ponsonnet, L., Reybier, K., Jaffrezic, N., Comte, V., Lagneau, C., Lissac, M., et al. (2003). Relationship between surface properties (roughness, wettability) of titanium and titanium alloys and cell behaviour. Mater. Sci. Eng. C 23, 551-560. doi: 10.1016/S0928-4931(03)00033-X

Ravenscroft-Chang, M. S., Stohlman, J. M., Molnar, P., Natarajan, A., Canavan, H. E., Teliska, M., et al. (2010). Altered calcium dynamics in cardiac cells grown on silane-modified surfaces. Biomaterials 31, 602-607. doi: 10.1016/J. BIOMATERIALS.2009.09.084

Rebl, H., Finke, B., Ihrke, R., Rothe, H., Rychly, J., Schroeder, K., et al. (2010). Positively charged material surfaces generated by plasma polymerized allylamine enhance vinculin mobility in vital human osteoblastss. Adv. Eng. Mater. 12, B356-B364. doi: 10.1002/adem.200980070

Rebl, H., Finke, B., Lange, R., Weltmann, K.-D., and Nebe, J. B. (2012). Impact of plasma chemistry versus titanium surface topography on osteoblast orientation. Acta Biomater. 8, 3840-3851. doi: 10.1016/J.ACTBIO.2012.06.015

Rebl, H., Finke, B., Schmidt, J., Mohamad, H. S., Ihrke, R., Helm, C. A., et al. (2016). Accelerated cell-surface interlocking on plasma polymer-modified porous ceramics. Mater. Sci. Eng. C 69, 1116-1124. doi: 10.1016/J.MSEC.2016. 08.016

Rico, P., Hernández, J. C. R., Moratal, D., Altankov, G., Pradas, M. M., and Salmerón-Sánchez, M. (2009). Substrate-induced assembly of fibronectin into networks: influence of surface chemistry and effect on osteoblast adhesion. Tissue Eng. Part A 15, 3271-3281. doi: 10.1089/ten.tea.2009.0141

Schulz, A., Katsen-Globa, A., Huber, E. J., Mueller, S. C., Kreiner, A., Pütz, N., et al. (2018). Poly(amidoamine)-alginate hydrogels: directing the behavior of mesenchymal stem cells with charged hydrogel surfaces. J. Mater. Sci. Mater. Med. 29:105. doi: 10.1007/s10856-018-6113-x

Secchi, A. G., Grigoriou, V., Shapiro, I. M., Cavalcanti-Adam, E. A., Composto, R. J., Ducheyne, P., et al. (2007). RGDS peptides immobilized on titanium alloy stimulate bone cell attachment, differentiation and confer resistance to apoptosis. J. Biomed. Mater. Res. Part A 83A, 577-584. doi: 10.1002/jbm.a. 31007
Shelton, R. M., Rasmussen, A. C., and Davies, J. E. (1988). Protein adsorption at the interface between charged polymer substrata and migrating osteoblasts. Biomaterials 9, 24-29. doi: 10.1016/0142-9612(88)90065-8

Sjaastad, M. D., and Nelson, W. J. (1997). Integrin-mediated calcium signaling and regulation of cell adhesion by intracellular calcium. Bioessays 19, 47-55 doi: 10.1002/bies.950190109

Skalak, R., and Shu, C. (1986). Electromechanical Effects in Bone. Handb. Bioeng. Available online at: https://www.ideals.illinois.edu/handle/2142/25222 (accessed April 14, 2020).

Staehlke, S., Koertge, A., and Nebe, B. (2015). Intracellular calcium dynamics dependent on defined microtopographical features of titanium. Biomaterials 46, 48-57. doi: 10.1016/J.BIOMATERIALS.2014.12.016

Staehlke, S., Rebl, H., Finke, B., Mueller, P., Gruening, M., and Nebe, J. B. (2018). Enhanced calcium ion mobilization in osteoblasts on amino group containing plasma polymer nanolayer. Cell Biosci. 8:22. doi: 10.1186/s13578-018-0220-8

Staehlke, S., Rebl, H., and Nebe, B. (2019). Phenotypic stability of the human MG-63 osteoblastic cell line at different passages. Cell Biol. Int. 43, 22-32. doi: $10.1002 /$ cbin. 11073

Terzi, M. Y., Izmirli, M., and Gogebakan, B. (2016). The cell fate: senescence or quiescence. Mol. Biol. Rep. 43, 1213-1220. doi: 10.1007/s11033-016-4065-0

Tryoen-Tóth, P., Vautier, D., Haikel, Y., Voegel, J.-C., Schaaf, P., Chluba, J., et al. (2002). Viability, adhesion, and bone phenotype of osteoblast-like cells on polyelectrolyte multilayer films. J. Biomed. Mater. Res. 60, 657-667. doi: 10. 1002/jbm.10110

von der Mark, K., and Park, J. (2013). Engineering biocompatible implant surfaces: Part II: cellular recognition of biomaterial surfaces: lessons from cell-matrix interactions. Prog. Mater. Sci. 58, 327-381. doi: 10.1016/J.PMATSCI.2012.09. 002

Webb, K., Hlady, V., and Tresco, P. A. (1998). Relative importance of surface wettability and charged functional groups on NIH 3T3 fibroblast attachment, spreading, and cytoskeletal organization. J. Biomed. Mater. Res. 41, 422-430. doi: 10.1002/(SICI)1097-4636(19980905)41:3<422::AID-JBM12<3.0.CO;2-K

Wennerberg, A., and Albrektsson, T. (2009). Effects of titanium surface topography on bone integration: a systematic review. Clin. Oral Implants Res. 20, 172-184. doi: 10.1111/j.1600-0501.2009.01775.x

Zimmerman, E., Geiger, B., and Addadi, L. (2002). Initial stages of cell-matrix adhesion can be mediated and modulated by cell-surface hyaluronan. Biophys. J. 82, 1848-1857. doi: 10.1016/S0006-3495(02)75535-5

Zou, W., Yang, S., Zhang, T., Sun, H., Wang, Y., Xue, H., et al. (2015). Hypoxia enhances glucocorticoid-induced apoptosis and cell cycle arrest via the PI3K/Akt signaling pathway in osteoblastic cells. J. Bone Miner. Metab. 33, 615-624 doi: 10.1007/s00774-014-0627-1

Conflict of Interest: The authors declare that the research was conducted in the absence of any commercial or financial relationships that could be construed as a potential conflict of interest.

Copyright (c) 2020 Gruening, Neuber, Nestler, Lehnfeld, Dubs, Fricke, Schnabelrauch, Helm, Müller, Staehlke and Nebe. This is an open-access article distributed under the terms of the Creative Commons Attribution License (CC BY). The use, distribution or reproduction in other forums is permitted, provided the original author(s) and the copyright owner(s) are credited and that the original publication in this journal is cited, in accordance with accepted academic practice. No use, distribution or reproduction is permitted which does not comply with these terms. 